\title{
Innovative Approaches to the Relationship Between Diet and Mandibular Morphology in Primates
}

\author{
Callum F. Ross • Jose Iriarte-Diaz • Charles L. Nunn
}

Received: 3 June 2011 / Accepted: 8 March 2012 / Published online: 22 May 2012

(C) Springer Science+Business Media, LLC 2012

\begin{abstract}
Attempts to establish relationships between mandibular morphology and either traditional dietary categories or geometric and material properties of primate diets have not been particularly successful. Using our conceptual framework of the feeding factors impacting mandibular morphology, we argue that this is because dietary categories and food geometric and material properties affect mandibular morphology only through intervening variables that are currently poorly understood, i.e., feeding behavior, mandibular loading, and stress and strain regimes. Our studies of 3-dimensional jaw kinematics in macaques and capuchins show that, although jaw movement profiles during chewing are affected by food material properties and species-level effects, patterns of jaw movements in these two species are broadly similar. However, because mandibular loading, stress, and strain regimes are determined by interactions between feeding behavior (such as jaw kinematics) and mandibular morphology, it is difficult to say whether these similarities in chewing kinematics also mean similarities in loading, stress, and strain. Comparative analyses of the scaling of daily feeding time and chew cycle duration reveal only weak support for the hypothesis that larger primates chew more than smaller primates. Consideration of these results suggests that better data are needed on the relationship between dietary categories, food material and geometric properties, the amount of time/cycles associated with different feeding behaviors (ingestion, premolar biting, mastication), and mandible stress and strain patterns if we are to understand fully relationships between mandibular morphology and diet in primates.
\end{abstract}

Keywords Dietary categories $\cdot$ Feeding behavior $\cdot$ Food properties $\cdot$ Mandibular morphology $\cdot$ Stress and strain

C. F. Ross $(\bowtie) \cdot J$. Iriarte-Diaz

Department of Organismal Biology \& Anatomy, University of Chicago, Chicago, IL 60637, USA e-mail: rossc@uchicago.edu

C. L. Nunn

Department of Human Evolutionary Biology, Peabody Museum, Harvard University, Cambridge, MA 02138, USA 
Several decades of research have established convincing empirical and theoretical relationships between proportions of foods in primate's diets (dietary categories) and their dental morphology and microwear (Kay 1975, 1984, 1985; Kay and Hylander 1978; Kay and Ungar 1997; Lucas 1979, 2004; Lucas and Teaford 1994; Lucas et al. 2008; Strait 1993a,b; Taylor 2002; Ungar 2004; Ungar and Spencer 1999; Ungar and Sponheimer 2011; Vogel et al. 2008; Yamashita 2008). Relationships between dietary categories and cranial morphology are less clear and are largely limited to differences in the mechanical advantage of jaw adductors (Antón 1996; Hylander 1979a; Ravosa $1988,1990,1996 a)$. One possible reason for this is the multiplicity of functions the cranium must perform, including protecting the brain, and orienting, insulating, and protecting the eyes, ears, and nose (Hylander et al. 1991b; Hylander and Ravosa 1992; Ravosa 2000; Ross 2001; Ross and Metzger 2004; Ross and Hylander 1996; Ross et al. 2011; Strait et al. 2009; Wroe et al. 2007). In contrast, because mandibles perform fewer functions than crania, mandibular morphology should be more closely related to diet than is cranial morphology.

Physiological and developmental data also suggest that mandibular morphology should be related to diet. High bone strain magnitudes in the primate mandible during mastication of "tougher" or "harder" foods suggest that the morphology of the high strained areas might covary with primate diet (Hylander 1979b; Hylander et al. 1991a; Hylander and Johnson 1997; Ravosa 2000; Ross and Hylander 1996; Ross et al. 2011). Developmental studies show that subadult macaques fed hard biscuits develop deeper mandibular corpora under $\mathrm{M}_{2}$, thicker cortical bone, and more evidence of remodeling in the mandible than animals eating food "with the consistency of fudge" (Bouvier and Hylander 1981b). Similarly, rabbits eating tougher or harder foods experience higher mandibular corpus strain magnitudes (Weijs and De Jong 1977) and display a raft of adaptive changes to muscles, mandibular mineralization, and cartilage and bone morphology, including wider and longer mandibular condyles, thicker mandibular corpora, deeper and wider symphyses, and thicker cortical bone at the symphysis (De Jong 2011; de Jong et al. 2010; Ravosa et al. 2007, 2010; Taylor et al. 2006). Together, these studies suggest that dietary categories should be associated with mandible morphology through developmental plasticity and/or genetic assimilation.

Despite this promise, the comparative morphological data do not, in our opinion, constitute evidence for strong relationships between dietary categories and mandibular morphology in primates. Among Old World monkeys, folivorous diets are associated with relatively wide mandibular condyles and relatively deep mandibular corpora and symphyses (Bouvier 1986a; Hylander 1979a; Ravosa 1990, 1996b), and among extant strepsirrhines folivory is associated with deeper and wider mandibular corpora and symphyses (Ravosa 1991; Ravosa did not compare condylar dimensions). However, among platyrrhines folivory is not associated with greater mandibular corpus depth (Bouvier 1986b). Rather, among platyrrhines deeper corpora are associated with seed predation; folivory and seed predation are associated with wider corpora (Kay et al. 2004). "Hard object feeding" is also associated with deeper mandibular corpora in mangabeys (Bouvier 1986a; Daegling and McGraw 2000; Hylander 1979a), with relatively deeper corpora, and greater condylar and symphyseal dimensions in pitheciines (Bouvier 1986b), and with greater strength and stiffness of the mandibular corpus and symphysis of Cebus apella compared with other 
Cebus (Bouvier 1986b; Daegling 1992). This extensive overlap in mandibular morphology between folivores and hard object feeders (Hogue 2008; Ravosa 1996a) suggests that mandibular morphology is only imprecisely related to diet.

Morphometric comparisons of a greater number of mandibular variables also fail to reveal strong relationships between diet and mandible morphology. Morphological differences between the mandibles of sympatric colobines that eat more (Procolobus badius) or fewer (Colobus polykomos) hard seeds do not match biomechanical predictions (Daegling and McGraw 2001). Out of 14 morphological variables estimating strength and stiffness of the mandible, none showed significant differences between both sexes of the two species, and some yielded the opposite of the predicted results. Morphological differences between mandibles of Lophocebus, which use more incisal preparation, and Cercocebus agilis, which perform more postcanine crushing of hard seeds (Shah 2003), are unremarkable (Daegling and McGraw 2007). Out of 11 morphological variables estimating strength and stiffness of the mandible, only two are significant: Lophocebus has deeper, narrower corpora at $\mathrm{M}_{2}$ and Cercocebus has a deeper symphysis relative to bicanine breadth (Daegling and McGraw 2007). Similarly, the distribution of cortical bone in hominoid mandibles reveals "no clear relationship between bone mass and the presumed severity of the masticatory loading environment" (Daegling 2007, p. 61). Taylor measured 20 biomechanically relevant morphometric aspects of the masticatory apparatus of great apes, and found that Gorilla gorilla beringei, the most folivorous, has a buccolingually wider corpus and symphysis, a higher temporomandibular joint (TMJ), and a large masseter attachment area on the mandible; however, these features are not universally linked to folivory in great apes (Taylor 2002). Similarly, the largest Hapalemur species, $H$. simus, does have comparatively deeper and wider mandibular corpora and symphyses than does H. griseus (Ravosa 1991, 1992), along with the highest bite forces and toughest diets (Vinyard et al. 2008b), but not all more folivorous strepsirrhines (Eulemur fulvus, E. macaco, Varecia variegata) have deeper and wider corpora and symphyses than their less folivorous close relatives (Ravosa 1991).

\section{What Accounts for the Weak Relationships Between Dietary Categories and Mandibular Morphology in Primates?}

Figure 1 presents a conceptual framework for the relationships between mandibular morphology and nested sets of feeding variables. Interspecific variation in dietary categories will be exclusively and consistently associated with specific variations in mandibular morphology only when: dietary categories are exclusively and consistently associated with variations in food material and geometric properties; these properties are exclusively and consistently associated with variations in feeding behaviors; these behaviors are exclusively and consistently associated with variation in the orientation, magnitude, and/or intensity of the external forces acting on the mandible; and these loading regimes are exclusively and consistently associated with variation in patterns of internal stress and strain. "Exclusively" means that members of different categories at one hierarchical level do not share membership of categories at a lower (inner) hierarchical level. For example, dietary categories do not share food 


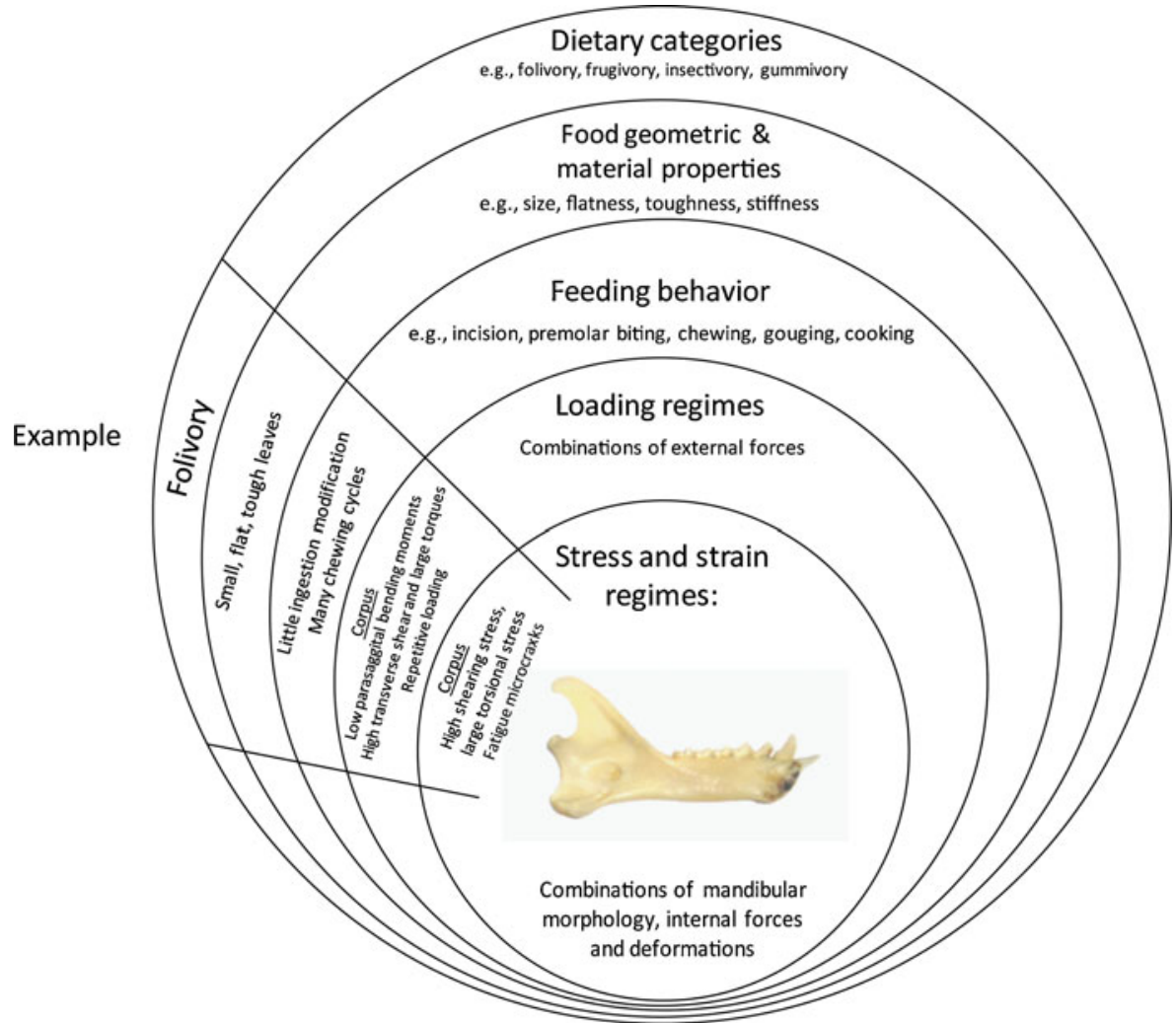

Fig. 1 Diagram of conceptual relationships between mandibular morphology (center), and, from outside in, dietary categories, food geometric and material properties, feeding behavior, mandibular loading regimes (combinations of external forces), and mandibular stress and strain regimes (combinations of internal forces and deformation regimes) (Ross et al. 2011). Dietary categories will map exclusively and consistently to mandibular morphology if 1 ) there are exclusive and consistent associations among dietary categories, food geometric and material properties, feeding behavior, loading regimes, and stress and strain regimes; 2) natural selection selects for these features of mandibular morphology because they improve feeding performance and fitness; and 3) these selective forces act in the same morphological and behavioral context, in part defined by phylogenetic history. One example is given, for folivory.

geometric or material properties, different food properties do not elicit the same behaviors, etc. "Consistently" emphasizes that relationships across nested sets will be always or commonly seen, including among different phylogenetic groups.

Using this formalism, there can be - and are - many reasons why dietary categories do not map consistently and exclusively to specific mandible morphologies. Here we only concentrate on a few of these, beginning from the periphery and working our way in toward the center (Fig. 1). Dietary categories will not map exclusively to mandibular morphology if these categories include foods with a wide range of different geometric and material properties, eliciting different feeding behaviors, loading regimes, and stress patterns. For example, the absence of relatively deep corpora and condylar specializations in Alouatta and the lack of relatively deep corpora in some folivorous strepsirrhines may be because the leaves they eat are not particularly tough (Bouvier 1986b; Ravosa 1991). If this is the case, studies of food 
material and geometric properties should be helpful in specifying relationships between these aspects of diet and mandible morphology.

However, a recent burgeoning of interest in measurement of food material properties (FMPs) (Darvell et al. 1996; Lucas 2004; Lucas et al. 2001, 2009) has not revealed consistent and exclusive relationships between FMPs and mandible morphology. The Bouvier/Ravosa hypothesis presented in the previous paragraph is supported by the finding that Hapalemur simus has the toughest diets (Vinyard et al. 2008b), but it is not supported by the fact that among congeneric Cebus the toughest diets are not associated with the largest corpora and symphyses (Wright et al. 2009), and across platyrrhines dietary toughness is not significantly related to mandibular robusticity (Norconk et al. 2009). Among great apes, out of five separate estimates of the load resistance properties of the mandible and five different specific food material property measures, significant relationships were found only between resistance to bending and torsion and "maximum $R$ [toughness] of non-leaf, non-fruit vegetation" (Taylor et al. 2008). Unless one invokes (as yet untested) clade-specificity of mandibular adaptations to FMPs, these weak, indirect, or nonexistent relationships between FMPs and morphology of the mandible suggest that food material properties alone do not predict mandibular morphology (Daegling and Grine 2006).

This brings us to the next level in our conceptual hierarchy: feeding behavior. Even if food geometric and material properties do map consistently to dietary categories, food material properties will not map exclusively onto mandibular morphology if they are not exclusively and consistently related to different feeding behaviors that produce different loading regimes and patterns of mandibular stress and strain, such as relative numbers of incision, premolar biting, and mastication cycles, the number of chewing cycles per day, overall bite force magnitudes, muscle activity patterns, and/or occlusal and joint morphology. Several workers have pointed out the importance of variation in feeding behavior for understanding variation in mandibular morphology. Daegling and colleagues have argued on a number of occasions that the homogeneous distribution of cortical bone in anthropoid mandibles might reflect homogeneity of masticatory stress environments (Daegling 2002; Daegling and McGraw 2001, 2007; Vinyard and Ryan 2006). Platyrrhine genera engaged in high-force, large-gape ingestive behaviors (Cebus and pitheciines) have enlarged jaw elevator muscles (Taylor and Vinyard 2009) and more robust mandibles than larger bodied folivorous primates (Norconk et al. 2009). The large gapes required for gouging behavior in callitrichids appear to exert a more powerful influence on mandibular and muscle morphology than do requirements for high forces (Taylor and Vinyard 2004; Taylor and Vinyard 2008; Vinyard et al. 2003; Vinyard and Ryan 2006). Differences in mandibular morphology between Lophocebus and Cercocebus likely reflect greater use of postcanine crushing by Cercocebus and greater use of incisal preparation by Lophocebus (Shah 2003) rather than dietary properties per se (Daegling and McGraw 2007). Similarly, it has been argued that differences in mandibular morphology between Cebus apella and C. capucinus are due not solely to the physical properties of the diets of these two species, but to "the manner of food preparation" (Daegling 1992). If these authors are correct, then an important key to understanding relationships between dietary categories and mandibular morphology is a better understanding of relationships between dietary categories, food geometric 
and material properties, and feeding behavior: i.e., data on what primates are eating, how they are ingesting it and how they are chewing it, including kinematics (gape), muscle activity, bite point, number of ingestion bites, and number of chews (Taylor et al. 2008).

The most important relationships to understand are those between variation in feeding behavior and variation in mandibular loading, stress, and strain regimes. Variation in feeding behavior will be associated with variation in mandibular morphology only if different feeding behaviors are associated with different patterns of external and internal forces, and these result in different patterns of mandibular stress and strain. This variation is poorly understood because mandibular bone strain patterns are known only from restricted areas of the mandible during a small number of feeding behaviors in a limited number of species (Vinyard et al. 2011). The available data in macaques suggest that there is less variance in strain orientations associated with ipsilateral mastication on different foods than there is between mastication and ingestion (Hylander 1979b, his Table 10), and there are also significant differences between working and balancing side strain orientations. More significantly, perhaps, it is not even clear that morphometric comparisons aimed at assessing relative mandibular strength in different species should even compare homologous regions: if different species emphasize different feeding behaviors to different degrees, their mandibles may well display morphological adaptations to diet in different parts of the mandible (Vinyard et al. 2011).

Dietary categories will also not map exclusively to mandibular morphology if different feeding behaviors by animals in different dietary categories can produce similar loading, stress, and strain regimes, predicting similar morphologies for different reasons. This might explain the morphological similarities between hard object feeders and folivores listed in the preceding text (Ravosa 1996a), and may underlie uncertainty about whether, e.g., robust australopithecines, were adapted for generating high bite forces, or chewing for long periods of time (Hylander 1988).

Finally, the lack of consistent relationships between dietary categories and mandible morphology may be due to clade-specific differences in relationships between any of these levels (Bouvier 1986b; Ravosa 1991). For example, folivory in hominids may require broader mandibular corpora; folivory in Old World monkeys and strepsirrhines may require deeper corpora; and folivory in platyrrhines may be possible because they inherited sufficiently deep mandibular corpora from a platyrrhine common ancestor that evolved a deep corpus for "other" reasons. At the innermost level of our conceptual hierarchy, similar loading regimes may result in different patterns of stress and strain in mandibles with clade-specific differences in morphology. This possibility is as yet untested, but finite-element modeling provides one possible method for such analyses. Clade-specific effects on relationships between levels of this hierarchy are reasonable in theory: after all, different clades could respond differently to the same selective pressure because of their different morphological or behavioral contexts. However, until these ancillary hypotheses are evaluated and corroborated - What is the biomechanical reason for deeper corpora in platyrrhines? Why is hominid folivory associated with wider corpora? - associations between dietary categories and mandibular morphology are called into question. 


\section{Questions}

In the context of this conceptual framework, we are pursuing experimental and comparative approaches to the study of feeding behavior in wild and laboratory primates to shed new light on relationships between diet and mandibular morphology in primates. One question we are addressing is whether variation in FMPs is an important determinant of variation in jaw kinematics and, hence, mandibular morphology. The underlying assumption is that differences in jaw kinematics are associated with differences in mandibular stress, and hence result in differences in mandibular morphology (Hylander 1988; Teaford and Ungar 2000; Ungar et al. 2006). For example, if the more vertically oriented jaw movements in humans eating tougher foods (Agrawal et al. 1998, 2000; Lucas 2004) are also seen in other primates, it would explain why the mandibles of folivorous primates are deeper than those of other primates. However, differences in jaw kinematics and bite reaction forces may also be related to interspecific differences in occlusal or TMJ morphology. Hylander hypothesized that colobines chew with more vertically oriented bite forces because their high cusped teeth prevent significant lateral displacements during the power stroke of mastication (Hylander 1979a, 1988). He argued that during occlusion, medial displacement of the mandible and its teeth is due to the interaction between vertically oriented bite forces and occlusal morphology, i.e., occlusal morphology guides jaw movement; bite forces are primarily vertically oriented; and the mandible experiences powerful sagittal bending moments, which the colobine mandible can resist because it is deeper. In contrast, in primates such as australopithecines with very flat occlusal surfaces, transverse movements during occlusion are produced by large transversely oriented components of muscle force; these produce large laterally directed bite forces, resulting in greater torsion of the corpus and greater lateral transverse bending of the symphysis, which the symphysis and corpus can resist because they are buccolingually broader (Hylander 1988). The morphology of the TMJ might also impact external forces acting on the mandible, by affecting the orientation and magnitude of joint reaction forces during chewing (Terhune 2009; Terhune et al. 2011; Wall 1999). Here we use our data on the 3-dimensional (3D) movement of the lower incisors and condyles of the mandible during feeding in Cebus and Macaca to ask whether FMPs are important determinants of jaw kinematics during mastication across primate species with different morphologies.

We are also investigating whether increasing body size, more robust and more fused mandibular symphyses, deeper mandibular corpora, and increased use of balancing side jaw elevator muscles are linked to "tougher," "harder," or "more obdurate" diets through selection to reduce effects of fatigue loading of the mandible (Hylander 1979a, b, 1984; Hylander et al. 2011; Ravosa 1991). Folivorous diets are hypothesized to be not only "tougher," "harder," or "more obdurate," requiring higher bite forces and/or more chewing cycles to process a given volume, but also less nutritious, necessitating consumption of a greater volume of food (Hylander 1979a; Hylander et al. 2011; Ravosa 1991, 1992; Ravosa 2000). Researchers arguing for biomechanical links between size-related changes in diet and mandibular morphology have long noted that it is not clear whether these morphological features are linked to higher bite, muscle and joint reaction forces, a greater number of daily chewing cycles, or all of these (Bouvier and Hylander 1981a, b, 1984; Hylander 1979a, 1985; 
Ravosa 1991, 2000; Taylor et al. 2008). Here we apply new phylogenetic comparative methods (Nunn 2011; Organ et al. 2011) to determine whether the available data support the hypothesis that larger primates do in fact chew more every day than smaller primates.

\section{Methods}

\section{In Vivo Data Collection Methods}

To investigate the possibility that interspecific differences in jaw muscle architecture, skeletal geometry, and occlusal and TMJ morphology might affect jaw kinematic profiles independently of, or in interaction with, FMPs, we present data on two species of primates that we have been studying in the laboratory: Cebus with flat occlusal surfaces and relatively higher articular eminences, and Macaca with more high-crowned, bilophodont teeth and relatively lower articular eminences (Terhune 2010). The individuals used in this study were three captive bred adult male capuchins (Cebus apella) and two captive bred adult female macaques (Macaca mulatta). These sample sizes were deemed sufficient for the current article because the focus of the special issue of which it is a part is methods, because our primary focus is on intraindividual and interspecific (not interindividual) variance, and because laboratory-based studies of nonhuman feeding have been extraordinarily informative in the past, despite low sample sizes of individuals (Hylander 1979b; Hylander et al. 1991a, 2004; Ross 2001; Ross et al. 2011; Vinyard et al. 2008a).

Subjects were housed and studied at the University of Chicago in accordance with federal and state regulations of the United States and Animal Care and Use Protocols approved by the IACUC at University of Chicago. Animal housing and husbandry followed federal guidelines, with the exception of cage size, which exceeded minima established by regulatory agencies. Cebus were pair-housed, and macaques were singly housed. The subjects were trained to feed while restrained in a custom designed (macaques) of commercially available primate chair (Plas-Labs, 514-AG) and jacket (Lomir Biomedical). In both cases the restraint allowed the arms, head, and neck to move freely.

At least 1 month before data collection, under isofluorane anesthesia, we implanted four bone screws (Veterinary Orthopedic Implants, TI-ST 270.10) in the mandible and four in the cranium to provide anchor points for reflective markers (Reed and Ross 2010). Before each data recording session, we attached markers to the bone screws, with the subjects either sedated with medetomidine and ketamine subsequently reversed with atipamezole, anesthetized with isofluorane, or restrained to ensure investigator safety (Reed and Ross 2010). Once the monkeys were awake and alert, we recorded kinematic data while the subjects ate a variety of foods of measured material properties (given in Table 2 in Reed and Ross 2010). After the subjects were sacrificed (for reasons unrelated to this research), we obtained computed tomography (CT) scans of the heads of two subjects at The University of Chicago Medical Center using a Philips Brilliance Big Bore CT scanner at $120 \mathrm{kV} /$ $263 \mathrm{~mA}$ and $90 \mathrm{kV} / 350 \mathrm{~mA}$ for macaques and capuchins, respectively. A total of 357 (macaque) and 325 slices (capuchin) were produced with a slice thickness of $0.8 \mathrm{~mm}$ 
and an interslice separation of $0.4 \mathrm{~mm}$. The scans were segmented using Amira 5.4 (Visage Imaging $\mathrm{GmbH}$, Berlin, Germany), separating the cranium and the mandible into discrete entities that were input into Matlab for further analysis.

\section{In Vivo Data Extraction}

We fed the monkeys foods assigned to two separate groups (high-toughness and lowtoughness foods) (Reed and Ross 2010) and recorded and analyzed high-resolution 3D jaw kinematics as described previously (Iriarte-Diaz et al. 2011; Reed and Ross 2010). We analyzed mandibular movements in the standard four-phase gape cycle, consisting of fast close, slow close, slow open, and fast open (Hiiemae 1978; Hiiemae and Crompton 1985). We calculated the 3D movements of mandibular markers in the coordinate system of, i.e., relative to, the cranium. We digitized the midline position of the mesial border of the two lower incisors in the coordinate system of the mandibular markers and calculated the movement of this point in the cranial coordinate system. We defined the cranial coordinate system by fitting a plane through the occlusal surfaces of the upper teeth at minimum gape. We assigned the primary axis of this plane, the midline between the left and right tooth rows, the $Y$-axis of the cranium (positive forward), with the origin at the midpoint between the right and left mandibular condyles; we assigned the secondary axis of the plane the $X$-axis (positive to the right); and the $Z$-axis (positive vertical) is the cross-product of the $X$ and $Y$ axes. Thus, the $Y Z$ plane of the cranial coordinate system corresponds to the sagittal plane of the cranium. We defined the position of the rotated and centered cranial markers at minimum gape as the reference position, and at each time step, we rotated and translated the mandibular and cranial markers so that the cranial markers matched the position of the reference position, effectively "fixing" the cranium in 3D space. We then calculated the mandibular marker and lower incisor point positions with respect to the fixed-cranium coordinate system.

\section{Statistical Analyses of In Vivo Jaw Kinematic Data}

If differences in occlusal or musculoskeletal morphology necessitate differences in the jaw closing kinematics, then interspecific variance in jaw kinematics might be substantial (Hylander 1988; Kay and Hiiemae 1974). However, to quantify these effects precisely, interindividual, and intra-feeding-sequence effects also need to be controlled, requiring an analysis of variance in jaw kinematics among species, individuals, feeding sequences (on different foods), and gape cycles. To address our first question we used the results of a random, nested ANOVA model with four hierarchical factors: species, individuals nested within species, chewing sequences nested within species and individuals, and chewing cycles nested within all the previous factors ( $c f$. Vinyard et al. 2008a, b). The chewing sequences factor included variation associated with FMPs because we fed subjects only one food type at a time. We modeled variation among chewing cycles by considering chew number as a covariate (Doncaster and Davey 2007). The ANOVA design was unbalanced, i.e., unequal numbers of individuals and sequences, preventing the estimation of an exact significant test for the random factors (Searle et al. 2006; Sokal and Rohlf 1995), so we focused on the overall pattern of variation distributed among these hierarchical 
factors ( $c f$. Vinyard et al. 2008a, b). Because chew cycles cannot be replicated within a chewing sequence in this kind of experimental design, intercycle variation is confounded with the residual error of the model. Estimation of the components of variance by ANOVA can, in some cases, yield negative estimates, despite the fact that variance cannot be negative. Following Searle et al. (2006), we performed our analyses with a restricted maximum likelihood (REML) method that excludes the possibility of negative estimates of variance. We tested specifically for differences between species and between food types by using a mixed model, with species and food type as fixed factors. We nested individuals and sequences within species and individual, respectively, and considered them as random factors.

\section{Finite Helical Axis and Condylar Movements}

Using the mandibular marker position data, we computed the finite helical axis (FHA) of the mandible, the instantaneous axis of rotation of the mandible in $3 \mathrm{D}$ space, at 8-ms increments. Using a single-value decomposition method (Spoor and Veldpaus 1980), we calculated the FHA by determining the time-dependent rotation matrix, $R\left(t_{i}\right)$, and the translation vector, $\mathrm{v}\left(t_{i}\right)$, for the displacement of the mandibular markers from their position at one time-step, $\mathrm{x}\left(t_{i}\right)$ to the next time, $\mathrm{x}\left(t_{i+1}\right)$, so that

$$
\mathbf{x}\left(t_{\mathrm{i}+1}\right)=R\left(t_{\mathrm{i}}\right) \times\left(t_{\mathrm{i}}\right)+\mathbf{v}\left(t_{\mathrm{i}}\right)
$$

The FHA is thereby described by the orientation and position of a vector in space (Fig. 2 and see Fig. 5a) and the motion of the mandible is described as the combination of translation along the FHA and an angular rotation around the FHA. Because the FHA is undefined at very small angular rotations, we calculated only the FHA in which the rotation was larger than $0.7^{\circ}$. To assess the utility of the FHA, here we focus on the main differences and similarities between macaques and capuchins while feeding on one food type: almonds.

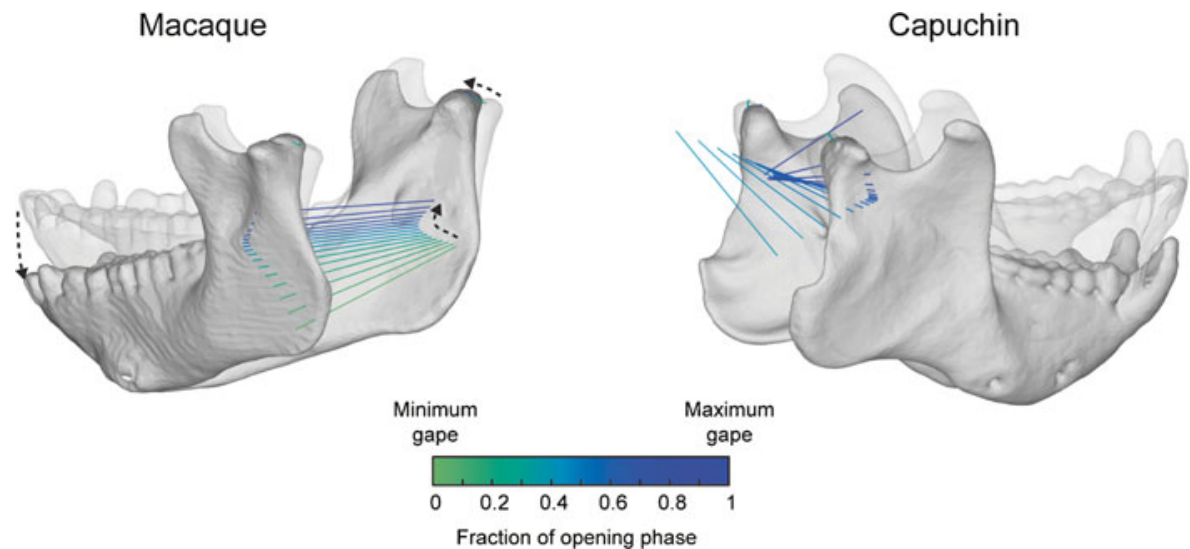

Fig. 2 Finite helical axes of macaque and capuchin monkeys during the opening phase of the gape cycle. Each line represents the FHA at a particular time during the opening phase and they are color-coded from minimum gape (green lines) to maximum gape (blue lines). Mandibles are not to scale to each other. (A color version of this figure is available online). 
These methods for quantifying rigid-body rotations and translations of the mandible during feeding allow quantification of movements of any point on the mandible whose coordinates relative to the mandibular markers can be defined (Gallo 2005; Gallo et al. 1997, 2000). We obtained these coordinates from the CT scans of the heads of two of our subjects, then used them to calculate the location of the condyle of the mandible during feeding in macaques and capuchins during chewing on hightoughness and low-toughness foods (Fig. 2).

\section{Phylogenetic Comparative Methods}

We used new comparative methods to estimate whether there are size-related changes in number of daily chewing cycles $\left(N_{\text {chews }}\right)$. If daily feeding durations consist entirely of chewing cycles, i.e., without any ingestion or swallow cycles, or if ingestion and swallow cycles have the same average duration as chewing cycles, then the number of chews per day $\left(N_{\text {chew }}\right)$ (dimensionless) is given by

$$
N_{\text {chews }}=\frac{T_{f \_ \text {secs }}}{T_{c}}
$$

where $T_{f \text { secs }},=$ daily feeding duration (in seconds) and $T_{c}=$ chew cycle duration (in seconds). We also investigated whether the scaling of $T_{f_{-} \text {secs }}$ is greater than the scaling of $T_{c}$.

Comparative data on scaling of daily feeding time and chew cycle duration were taken from our previous work (Ross et al. 2009a, b). Feeding time data were gathered from the literature and from personal communications (Ross, Reed et al. 2009a, b, their Table 2). We used feeding time data when "feeding time" was defined as moving food into the mouth, chewing, and swallowing. Foraging is the search for food, and in many species whose diets include a significant proportion of insects, this can account for a large percentage of their feeding budgets. Therefore, when collecting data for species for which foraging was deemed important, we included only studies that distinguished between feeding and foraging in the analysis. The data are dimensionless percentages of the time spent feeding during waking hours. For diurnal primates, this includes the $12 \mathrm{~h}$ between dawn and dusk; we included nocturnal species if the source clearly specified how changes in behavioral states were observed. We calculated average species feeding budgets when multiple activity budgets for the same species were available. To minimize seasonal effects on feeding time, we preferred data from studies of 6 months or longer, but used data from shorter studies if necessary.

We collected primate chew cycle time data from video recordings of freely moving primate subjects at zoos and primate centers, and from bone strain recordings of restrained individuals. This included 7748 chewing cycles from 426 chewing sequences by 86 individuals in 35 species of primates. We fed laboratory subjects a variety of food types cut into pieces of a size that could easily be fed to them with a pair of forceps. We filmed zoo animals eating the range of foods normally fed to them: we made no attempt to control food material properties. We estimated $T_{c}$, length of time between successive maximum gapes, from video records of complete chewing sequences (30 frames/s) or as the time between peak bone strain in the mandibular 
corpus (collected at a range of frequencies ranging from 1 to $10 \mathrm{KHz}$ ) (Ross 2001; Ross et al. 2007a, b). We calculated species means and presented them in the Appendix to Ross et al. (2009a, b).

We first used phylogenetic generalized least squares (PGLS) methods to examine the association between $T_{c}$ and body mass $\left(M_{b}\right)$ (Garland and Ives 2000; Nunn 2011; Pagel 1999). We used the resulting estimates of the slope and intercept to predict $T_{c}$ for species with data on body mass and $T_{f}$, where the latter was translated into seconds $\left(T_{f_{s} \text { secs }}\right)$ by dividing by 100 and multiplying by $12 \mathrm{~h} \times 60 \mathrm{~min} \times 60 \mathrm{~s}$. With those estimates of $T_{c}$ and $T_{f_{-} s e c s}$, we estimated the number of chews per day as $N_{\text {chews }}=T_{f_{-} \text {secs }} / T_{c}$, and then used PGLS to investigate whether $N_{\text {chews }}$ depends on body mass.

After calculating $N_{\text {chews }}$ for the species in our data set, it became apparent that Loris tardigradus showed an exceptionally low value for $T_{f}$, and parameter estimates for models that included Loris produced nonsensical results, especially for estimates of the intercept and effect of radiation, i.e., strepsirrhine vs. haplorhine; the coefficient for body mass was less strongly affected. We therefore present results that exclude Loris for analyses that involved $T_{f}$, i.e., the scaling of $N_{\text {chews }}$ and $T_{f_{\text {secs }} \text {. Once Loris }}$ was removed, primate radiation was not a compelling predictor, and so we do not include it in the results presented here. For statistical analyses, were $\log _{10}$ transformed all data

Our PGLS models incorporated phylogeny by representing the error term of the statistical model as a variance-covariance matrix that reflects the phylogenetic relationships among the species (Freckleton et al. 2002). We also estimated the parameter $\lambda$, which scales the internal branches of the phylogeny and serves as a measure of phylogenetic signal (Freckleton et al. 2002). The parameter $\lambda$ generally lies between 0 and 1 . When $\lambda=0$, this corresponds to a nonphylogenetic test because all internal branches are set to be 0 , i.e., collapsed, resulting in all species emanating from a common root node, i.e., a star phylogeny (Felsenstein 1985). Values of $\lambda>0$ represent increasing phylogenetic signal, with $\lambda=1$ indicating that the given branch lengths adequately account for variation in the trait under a Brownian motion model of evolution.

Because phylogenetic relationships and branch lengths are never known with certainty, and results may vary depending on the phylogenetic inference that is used (Lutzoni et al. 2001), results should not be conditioned on a single phylogenetic hypothesis (Huelsenbeck et al. 2000; Pagel and Lutzoni 2002). Here, we used a sample of 100 dated phylogenies from a recent Bayesian inference of primate phylogeny (Arnold et al. 2010), which can be accessed at http://10ktrees.fas. harvard.edu/. We obtained the trees from Version 3 of 10kTrees.

We sampled statistical models from a Bayesian posterior probability distribution. For this analysis, we fit regression models using the program BayesTraits (Pagel and Meade 2007). BayesTraits uses Markov Chain Monte Carlo (MCMC) to sample regression coefficient(s), the intercept, and $\lambda$, with a different tree randomly selected in each iteration of the chain. We ran the MCMC chain for 1,050,000 iterations and sampled parameter values every 100 iterations, discarding the first 50,000 iterations as "burn-in," i.e., after the MCMC analysis had clearly settled on a stationary distribution of parameter values from the posterior probability distribution. The models used uniform priors on regression coefficients ranging from -100 to 100 . 
We adjusted the "ratedev" parameter to obtain a mean acceptance rate between $20 \%$ and $40 \%$ (Pagel and Meade 2007). We performed all analyses three times to ensure convergence to the same distribution of parameter estimates, and report mean parameter estimates and $95 \%$ credible intervals from the first run. We used the program Tracer (Rambaut and Drummond 2003-2009) to confirm that the parameter values reached a stationary distribution, to ensure that burn-in had been reached, and to obtain credible intervals.

For each of our two predictions, we obtained 10,000 estimates of the regression coefficient(s), the intercept, and $\lambda$. These estimates reflect a posterior probability distribution of parameter estimates. We calculated the percentage of samples from the MCMC sample in which a parameter value, e.g., a regression coefficient, was in the predicted direction and report those percentages, along with the mean coefficient and $95 \%$ credible intervals for $\lambda$. If an independent variable has no effect on the dependent variable, we expect its coefficient will be equally represented as negative or positive. Thus, percentages closer to $100 \%$ reflect greater support for a prediction. In advance of running tests, we decided to interpret results with $>95 \%$ of regression coefficients in the predicted direction as "strongly supportive," between $90 \%$ and $<95 \%$ as "supportive," and between $85 \%$ and $<90 \%$ as "possible" support in need of investigation with larger sample sizes. By using both a sample of trees and a sample of regression coefficients, we control for phylogenetic uncertainty and uncertainty in the underlying statistical and phylogenetic models (Nunn 2011; Pagel and Lutzoni 2002).

\section{Results}

\section{Jaw Kinematics}

During $\mathrm{SO}, \mathrm{FO}$, and $\mathrm{FC}$ phases of the gape cycle the largest variance component in spatial kinematic parameters is between chewing cycles within chewing sequences, with minimal effects of species or food type (Fig. 3). In contrast, during SC there are consistent species-specific effects on vertical displacement of the mandible and consistent FMP effects on lateral displacement: macaques exhibit larger vertical excursions during SC than capuchins (Fig. 4a), and both species exhibit larger horizontal displacements during SC when eating low toughness foods (Fig. 4b).

In a hypothetical case of pure jaw elevation and depression, the FHA will be completely horizontal and aligned to the axis that connects the condyles. Any deviation of the FHA from horizontal implies lateral movement of the mandible. The position of the FHA also affects the magnitude of condylar displacement: the farther away from the TMJ the FHA is located, the larger the antero-posterior displacement of the condyle will be. The manner in which the orientation of the FHA changes through the gape cycle is similar in capuchins and macaques, although in capuchins the angular deviation of the FHA in the coronal plane, $(\alpha)$, often alternates among cycles, while in macaques the angular deviation is more consistent from cycle to cycle (Fig. 5b). The midsagittal point of the FHA is located anterior and inferior to the TMJ in both macaques and capuchins and the anteroposterior position of the FHA is similar in both species. However, superoinferiorly the FHA is located closer to the TMJ in capuchins than in macaques (Fig. 5b). These species-specific 


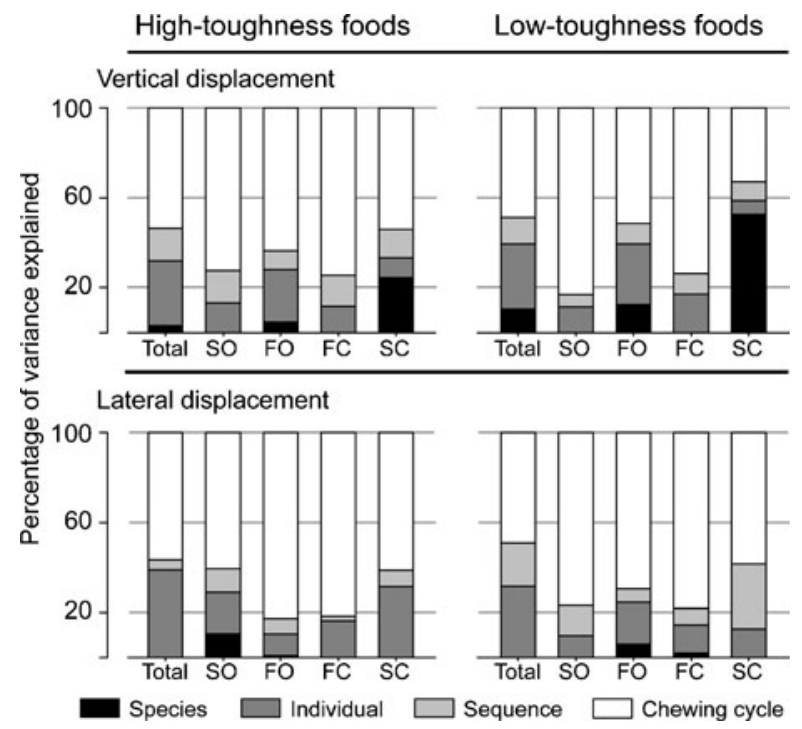

Fig. 3 The percentage of variance explained by each hierarchical factor in a nested ANOVA model for vertical and lateral displacement of the mandible when monkeys are feeding on high-toughness and lowtoughness foods. (Modified from Iriarte-Diaz et al. 2011).

differences are particularly clear during the opening phases of the gape cycle, when the FHA gets gradually closer to the TMJ in macaques but remains stationary for a considerable portion of the opening phase in capuchins (Fig. 5b).

These differences in FHA mean that macaques and capuchins differ in the anteroposterior displacements of their condyles during the gape cycle. These were more fully explored in a larger sample of chews on high- and low-toughness foods (Fig. 6). In both macaques and capuchins feeding on low-toughness foods, such as almonds, both condyles move anteriorly during opening at a similar rate, but the working-side condyle starts moving earlier, achieving a more anterior position at the end of opening. During closing, the working side condyle moves posteriorly at a relatively constant rate, whereas the balancing-side condyle moves backward more slowly after the start of SC. Thus, the working-side condyle reaches its posterior extremity while

A

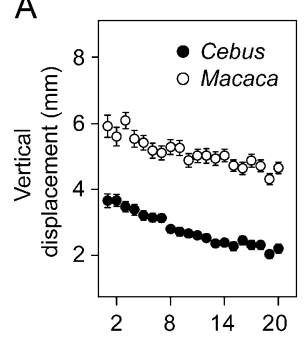

B

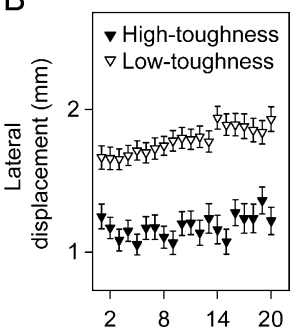

Fig. 4 (a) Mean vertical displacement during the 20 first chewing cycles for Macaca (open circles) and Cebus (closed circles). Because there were no effects of FMPs on vertical displacement, we pooled data from both high-toughness and low-toughness foods. (b) Mean lateral displacement of the mandible of macaques and capuchins feeding on high-toughness (closed triangles) and low-toughness (open triangles) foods. Because no species effect was found, we pooled data from macaques and capuchins. (Modified from Iriarte-Diaz et al. 2011). 
A

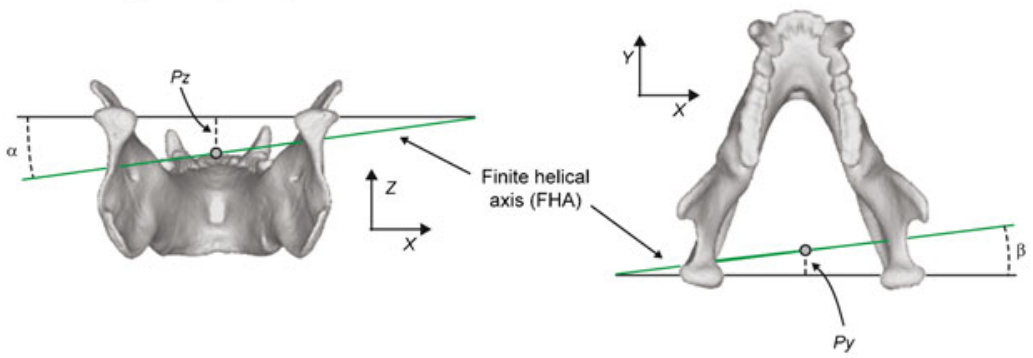

B

Macaque

Capuchin
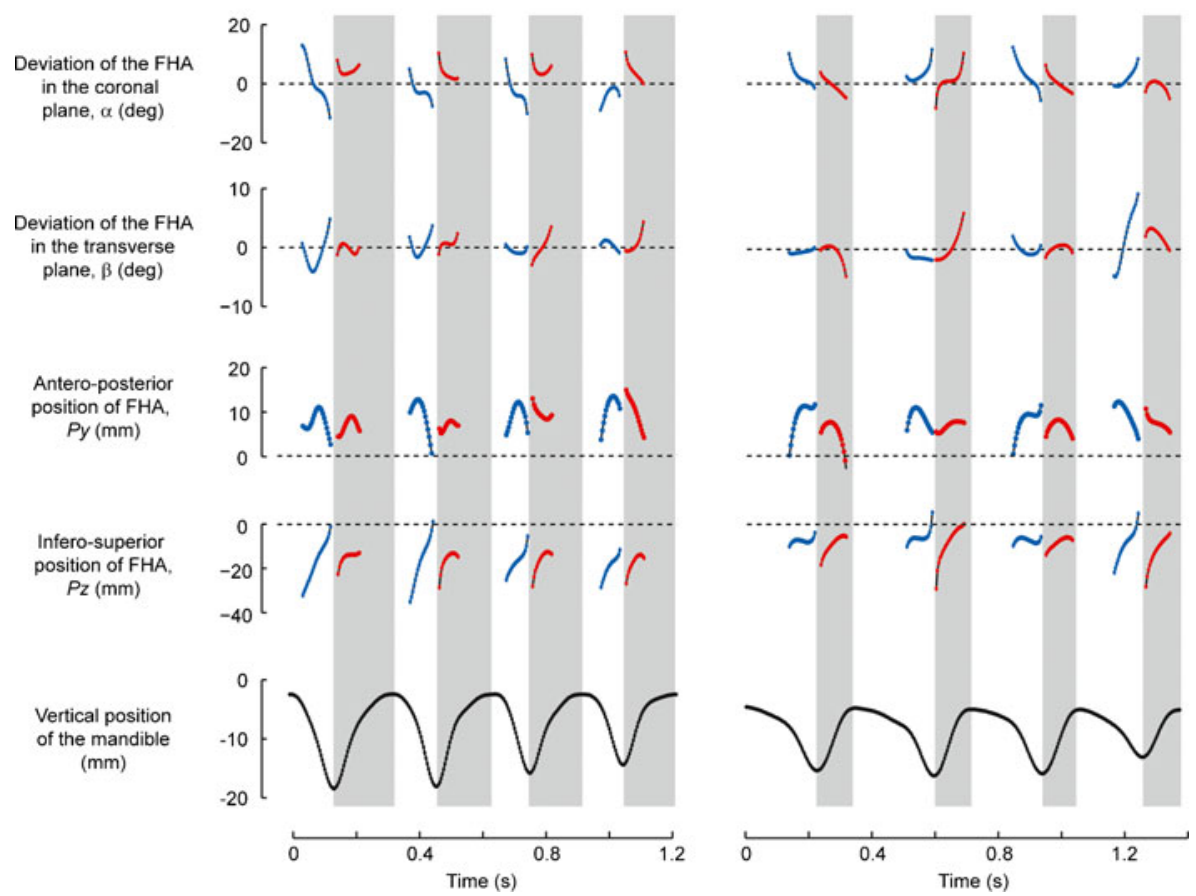

Fig. 5 (a) Diagram of the descriptors of the helical axis used in this study. Orientation of FHA (green line) is described as the angular deviation from the condylar axis (the black line connecting the heads of the condyles) in the coronal plane $(\alpha)$ and in the transverse plane $(\beta)$. The position of the FHA is described as the horizontal and vertical distance of the FHA from the condylar axis, $P y$ and $P z$, respectively. (b) Parameters describing the orientation and position of the FHA during four consecutive chewing cycles for a macaque and a capuchin monkey, while feeding on an almond. The shaded bars correspond to the closing phases of the gape cycle. Blue and red points correspond to the FHA parameters during opening and closing phases of the gape cycle, respectively. (A color version of this figure is available online).

the balancing-side condyle is still moving posteriorly, producing lateral displacement of the mandible toward the balancing side during the power stroke (Fig. 6). In macaques, condylar movement was similar to that observed during feeding on lowtoughness foods. The only difference was that during the closing phase the differences in movement rate between the working- and balancing-side condyles were smaller than when feeding on low-toughness foods. In contrast, in capuchins feeding 

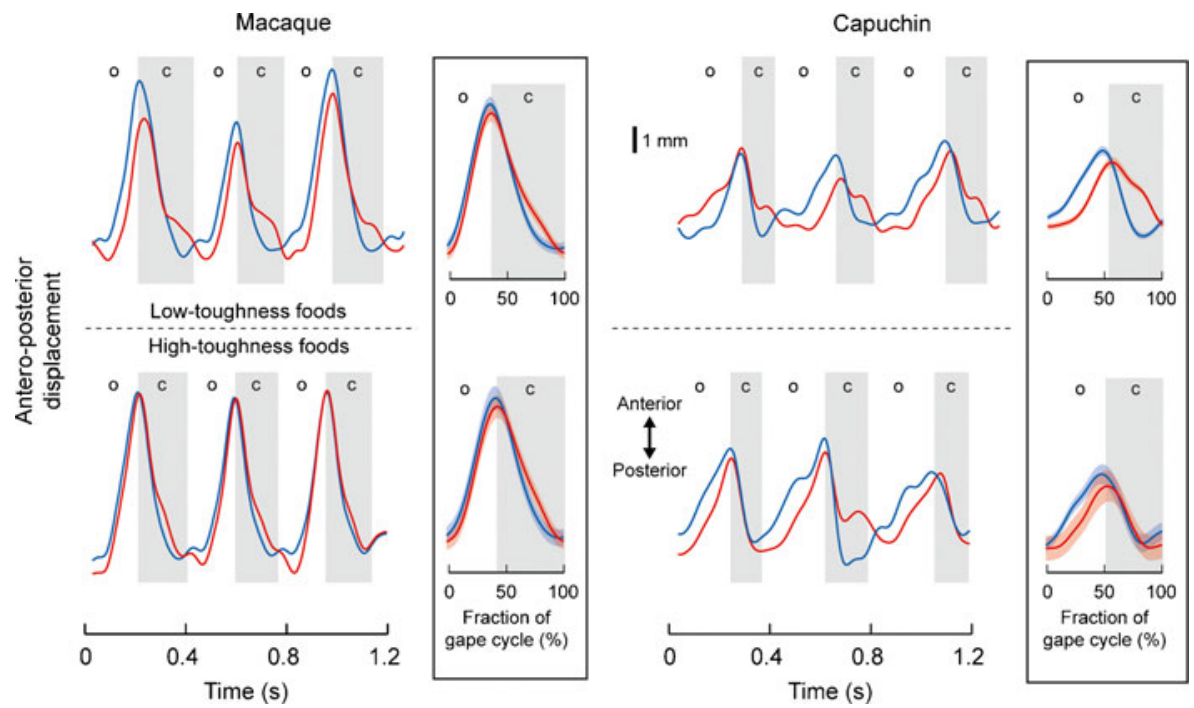

Fig. 6 Anteroposterior condylar displacement for macaque (left) and capuchin (right) monkeys feeding on foods of low- (upper) and high-toughness (lower). The blue and red lines correspond to representative traces of the anteroposterior movements of the working- and balancing-side condyles, respectively, during three consecutive chewing cycles. The shaded bars correspond to the closing phases (c) of the gape cycle and the white bars, the opening phases (o) of the gape cycle. The insets present the mean and standard error of the condylar displacements, over a normalized gape cycle, for the first five chewing cycles of a variable number of chewing sequences. For macaques, we used 248 and 63 cycles to calculate the mean condylar displacement for low- and high-toughness foods, respectively. We used 135 and 28 cycles to calculate the mean condylar displacement of capuchins feeding on low- and high-toughness foods, respectively. (A color version of this figure is available online).

on high-toughness foods, condylar displacements during closing were very different from those when feeding on low-toughness foods. During the closing phase, both working- and balancing-side condyles move posteriorly in a similar fashion, producing less lateral mandible displacement during the closing phase than that noted when feeding on low-toughness foods (Fig. 4b).

We also found that, while the absolute magnitudes of anterior-posterior movement are greater in the larger species (macaques) than the smaller (capuchins) as predicted by Wall (1999), the magnitudes relative to the mandibular fossa appear to be similar. Plotting these movements on CT scans of the TMJs of these two monkeys suggests that the condyles did not travel anteriorly out of the mandibular fossa in either monkey during these chews (Fig. 7). These data suggest that the anteroposterior dimensions of the mandibular fossa scale so as to accommodate size related differences in condylar excursions during mastication.

Scaling of $N_{\text {chew }}$

In our PGLS analyses of the scaling of $T_{c}$, we found strong evidence for a positive association between $T_{c}$ and $M_{b}$, with positive slopes in $>99 \%$ of the regression coefficients from the posterior probability distribution (Fig. 8a). The $95 \%$ credible interval on the slope ranged from 0.06 to 0.18 , with a mean of 0.1189 ; the mean of the posterior probability distribution for the intercept was -0.4854 . Body mass accounted 

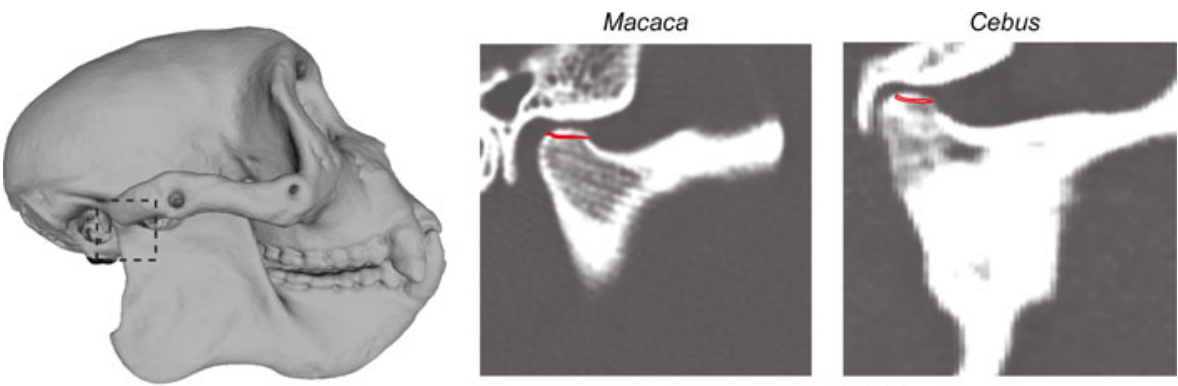

$5 \mathrm{~mm}$

Fig. 7 Parasagittal CT scans of the temporomandibular joint of Macaca and Cebus showing condylar movement trajectories during chewing. The CT scan was taken from the area highlighted in the 3D model on the left. The red traces represent the calculated displacement of the condyle through one complete gape cycle. Condyle displacement was estimated based on the movement of the mandible with the cranium fixed in space with the occlusal surface of the upper teeth horizontal and the CT scans were oriented in the same manner. (A color version of this figure is available online).

for $28 \%$ of the variation in $T_{c}$. We also found evidence for phylogenetic signal, with the mean $\lambda=0.69$ and a $95 \%$ credible interval that clearly excluded zero $(0.41-0.93$,
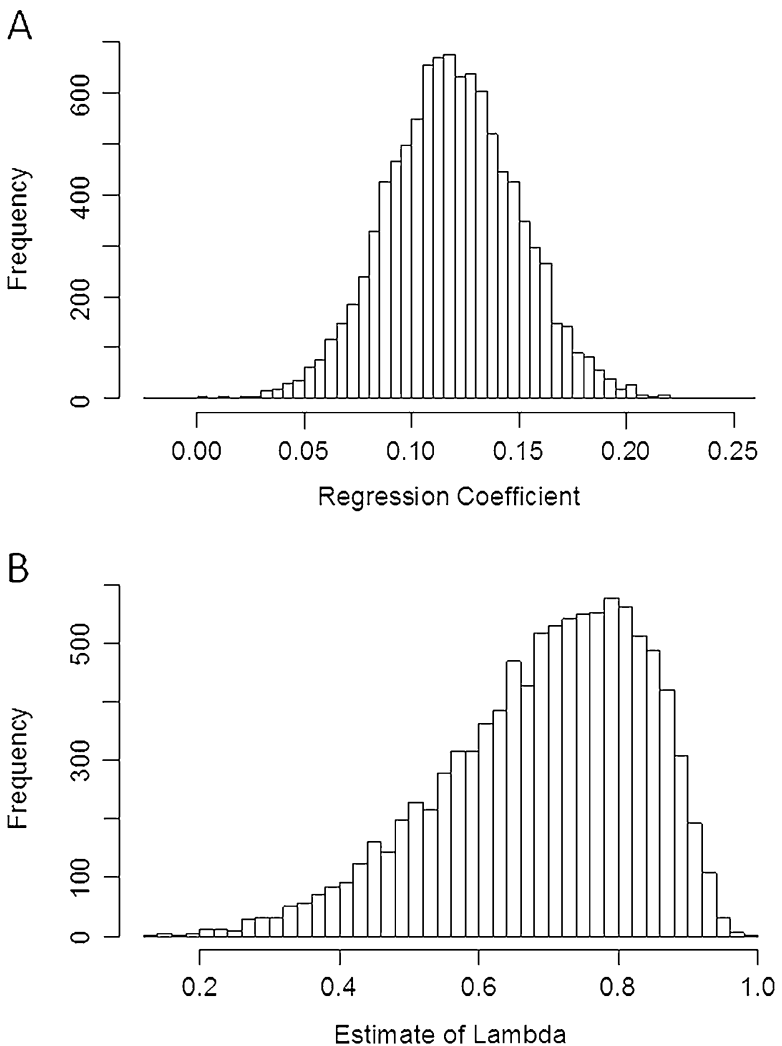

Fig. 8 Posterior probability distribution of (a) regression coefficients and (b) $\lambda$ for the scaling of $T_{c}$. Plots represent histograms of 10,000 estimates sampled using MCMC across a 100 phylogenies taken from 10kTrees (Arnold et al. 2010). The distribution of regression coefficients clearly departs from 0 , while the distribution of $\lambda$ differs from both 0 and 1 . 
Fig. 8b). We used the mean parameter estimates from the simpler model, i.e., log $\left(T_{c}\right)=-0.4854+0.1189 * \log M_{b}$, to predict $T_{c}$ for each species for which feeding time data were available. We then used this estimate to predict the number of chews per day $\left(N_{\text {chew }}\right)$, i.e., $T_{f_{-} \text {secs }} / T_{c}$, for each species.

Analyses of scaling of these $N_{\text {chew }}$ estimates yielded support for positive scaling with body mass: $90.1 \%$ of the regression coefficients in our posterior probability distribution were positive (Fig. 9a). Body mass accounted for only $2.2 \%$ of the variation in $N_{\text {chew }}$, with a mean regression coefficient of 0.062 (95\% credible interval of -0.036 to 0.155 ) and intercept of 4.702 . We again found compelling evidence for phylogenetic signal in the data, with a mean $\lambda$ of 0.60 and $95 \%$ credible intervals of $0.27-0.88$ (Fig. 9b).

These analyses rely on estimating $T_{c}$, which we accomplished by fitting a general linear model. As reported in the preceding text, however, this model accounted for only $28 \%$ of the variation in $T_{c}$, and thus our ability to predict $T_{c}$ is limited. Thus, we took an alternative approach in which we compared the slopes of the scaling of $T_{c}$ on mass and $T_{f \text { secs }}$ on mass, with the prediction that to maintain positive scaling for $N_{\text {chew }}$, the estimated slope of $T_{f_{-} \text {secs }}$ on mass is greater than the slope of $T_{c}$ on mass. We found that $T_{f_{-} \text {secs }}$ scales with body mass with a slope of 0.1804 , with a $95 \%$ credible interval 0.088 to $0.278(\lambda=0.6)$, and an intercept of 4.2161 . This relationship was strongly supported in the posterior probability distribution $(>99 \%$ of MCMC samples were positive), although the variance explained was low $\left(R^{2}=0.16\right)$. Thus, the estimated slope of $T_{f_{-} \text {secs }}$ on $M_{b}$ lies at the outer limit of the credible interval of the estimated slope of $T_{c}$ on mass. The actual distributions overlap considerably (compare Figs. 8a and 10), although it is highly unlikely that the two posterior probability
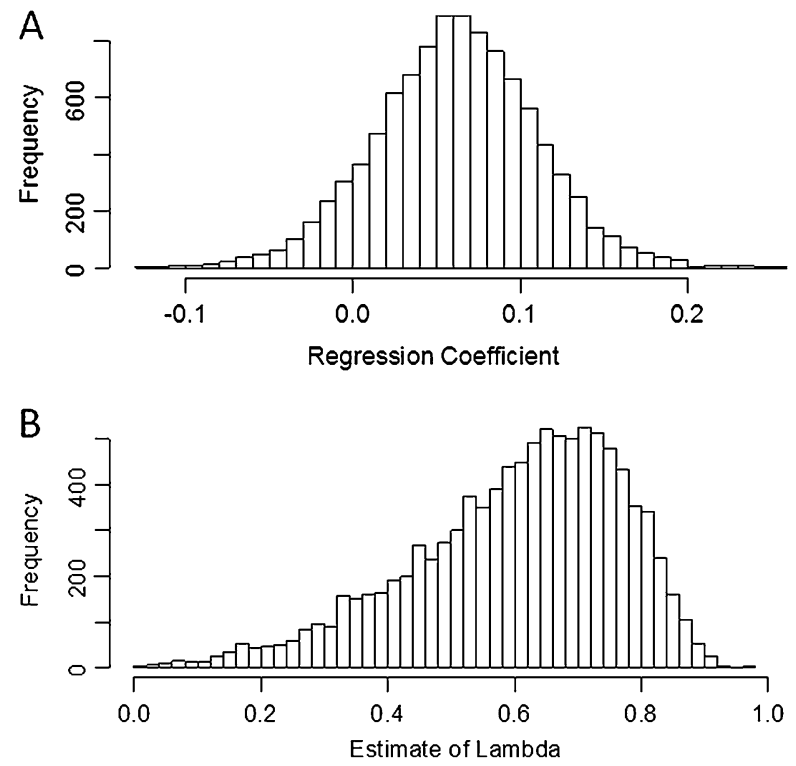

Fig. 9 Posterior probability distribution of regression coefficients for effects of (a) body mass and (b) $\lambda$ for the scaling of $N_{\text {chew. }}$ Plots represent histograms of 10,000 estimates sampled using MCMC across a 100 phylogenies taken from 10kTrees (Arnold et al. 2010). The distribution of regression coefficients shows greater overlap with 0 , while the distribution of $\lambda$ differs from both 0 and 1 . 


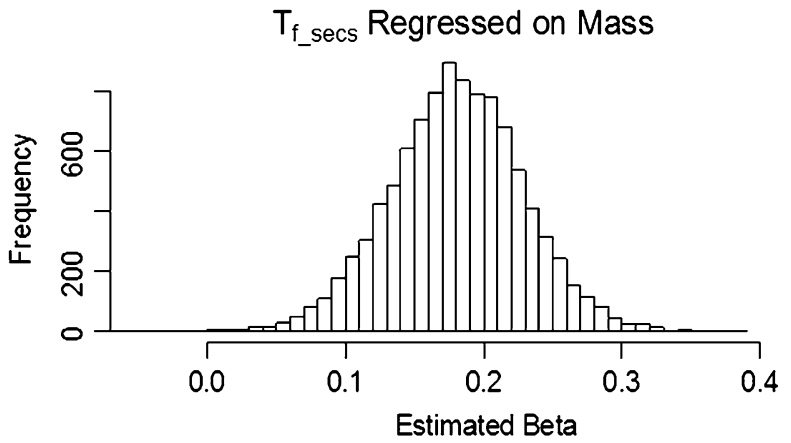

Fig. 10 Posterior probability distribution of regression coefficients for scaling of $T_{f_{-} \text {secs. }}$. Plot represents histograms of 10,000 estimates sampled using MCMC across 100 phylogenies taken from 10kTrees (Arnold et al. 2010). Compare to Fig. 8a for scaling of $T_{c}$, which is predicted to be smaller if the number of chews scales positively.

distributions come from the same underlying distribution (AIC of model with the same distribution $=-62,616$, compared to a model with different distributions $=$ $-71,860$, based on a general linear model of the posterior distribution of regression coefficients in the stats package of R (R-Development-Core-Team 2010) that fit a factor for radiation, compared to a model with only an intercept and thus assuming a common distribution).

\section{Discussion}

Our conceptual hierarchy of the feeding factors impacting mandibular morphology is presented in Fig. 1. Various workers have noted weak, indirect, imprecise, or nonexistent relationships between mandibular morphology at the base (center) of the hierarchy and either the outermost - dietary categories — or next level — food geometric and material properties - of this hierarchy (Brown 1997; Daegling and McGraw 2001; Daegling and Grine 2006; Daegling and McGraw 2007; Hogue 2008; Norconk et al. 2009; Taylor et al. 2008; Vinyard et al. 2011). We suggest that is because diet and FMPs impact mandible morphology only through changes in feeding behavior, loading regimes, and stress and strain regimes; and that there are currently not enough data on variation in these factors to allow a complete understanding of relationships between diet and mandible morphology. Here we present the results of studies using two novel experimental and comparative approaches that highlight areas where further data are needed.

\section{Jaw Kinematics}

The first novel approach uses precise measures of 3D jaw kinematics to evaluate the relative importance of species and FMP effects on jaw kinematics in primates. Our data reveal that the majority of variance in lateral displacement of the jaw during the chewing cycle is between chewing cycles within chewing sequences, not between chewing sequences on different foods. This reflects significant effects of changes in bolus properties -i.e., external physical attributes, including adhesive and cohesive 
properties, size, and shape - on kinematics through the chewing sequence (Foster et al. 2006; Plesh et al. 1986; Vinyard et al. 2008a; Woda et al. 2006a, b). These results recall Hiiemae and Kay's report of significant differences in durations of the gape cycle phases between puncture crushing and mastication chewing cycles (Hiiemae and Kay 1973). They are also congruent with a study by Vinyard and colleagues, who showed that the largest proportion of variance in the timing of peak activity in the jaw muscles is between chewing cycles within chewing sequences (Vinyard et al. 2008a). They reasonably attribute this to variation in food, i.e., bolus, external properties and bite location within chewing sequences, as well as redundancy in the way that the jaw muscles can be activated to produce submaximal bite forces. If these kinematic results also characterize intra- and intersequence variation in mandibular stress and strain regimes, it suggests that intrasequence variation in bolus properties might have a greater impact than FMPs on mandibular strain patterns during mastication.

When this intrasequence variation in jaw kinematics is controlled, FMPs impact SC jaw kinematics similarly in both species. As found by Agrawal et al. (2000), lowtoughness foods were eaten with greater lateral displacement of the mandible during SC. SC is the phase of the gape cycle when bite force is being generated, suggesting that FMPs may impact the external forces acting on the mandible, and hence its strain regimes and morphology. Whether this relationship also characterizes other taxa, whether this variance in kinematics is associated with variance in mandibular stress and strain patterns, and the importance of this variance relative to intrasequence and interspecific variance all remain to be determined. The available data suggest that food material properties have little impact on strain orientations in the corpus during mastication by macaques and alpacas (Hylander 1979b; Williams et al. 2011) (cf. Daegling and McGraw 2001).

We also found significant interspecific differences in jaw vertical displacement during SC, with macaques displaying the largest vertical excursions. We previously hypothesized that these differences may be related to interspecific differences in occlusal morphology, such as the higher cusps of macaques compared to the flatter occlusal profile of capuchins (Iriarte-Diaz et al. 2011). This would be congruent with Hylander's hypothesis that more high cusped occlusal surfaces might be associated with more vertically oriented bite forces (Hylander 1988; Ungar et al. 2006).

Our calculation of the mandible FHA during chewing revealed differences between the macaque and capuchin, especially during jaw opening. However, although FHA completely describes the movement of the mandible with respect to the cranium, at small angular deviations, e.g., during slow-close and slow-open phases, the physical interpretation of the FHA is nonintuitive. We find these differences easier to understand when considering movements of the mandibular condyles. Although the data presented here are based on only a small sample of chewing cycles from only two monkeys, the differences between these species in the magnitudes of condylar movements are quite subtle (Fig. 7). As predicted by Wall (1999), differences in size are associated with differences in displacement amplitude, but the condyle always remains within the mandibular fossa during mastication. Capuchins and macaques may generate transverse molar movements during the power stroke using subtly different timing of working and balancing condylar movements (Fig. 6), but it is not obvious that this is related to differences in mandibular fossa morphology (Terhune 2010; Wall 1995, 1999). 
Scaling of $N_{\text {chew }}$

Increases in dietary "toughness" and decreases in dietary quality with increasing body size have been argued to necessitate increases in the number of chew cycles per day, increasing the danger of fatigue damage to the mandible in primates (Hylander 1979a; Hylander et al. 2011; Ravosa 1991, 1992; Ravosa et al. 2000b). But do larger primates chew more than smaller primates? Using the scaling relationships in their Table 4, Ross et al. (2009a, b) estimated that $N_{\text {chew }} \propto M_{b}^{121}$, indicating increases in number of chews with body mass in primates. However, when primate phylogenetic relationships were taken into account, the relationship between body size and daily feeding time in primates was not significant (Ross et al. 2009b). If feeding time is a reasonable estimate of chewing time, this would suggest that larger primates do not feed or chew for longer every day than larger primates.

In contrast, using Bayesian PGLS methods, Organ et al. (2011) found a positive relationship between $T_{f}$ and $M_{b}$, motivating us to reanalyze both the feeding time and chew duration data. The analyses presented by Organ et al. differ from the previous ones by estimating phylogenetic signal, and then scaling the branch lengths to reflect that degree of phylogenetic signal, i.e., $\lambda$. Organ et al. also used a logit-transformation to deal with the fact that a percentage is bounded by 0 and 100 . Finally, the trees themselves differ, with Organ et al. using a sample of phylogenies from a new Bayesian inference of primate phylogeny (Arnold et al. 2010), rather than the single phylogenetic inference from (Ross et al. 2004).

In the present analysis, we followed Organ et al. (2011) by using Bayesian PGLS methods across a sample of trees and estimating $\lambda$. The results of these new analyses suggest that $T_{c}$ increases with $M_{b}$ as $T_{c} \propto M_{b}^{119}$, with a $95 \%$ credibility interval that excludes the exponent of Ross et al. Using this relationship and the estimates of $T_{f}$ from Ross et al., $N_{\text {chew }}$ is estimated to increase with body mass as $\log _{10} N_{\text {chew }}=4.702+0.062 * \log _{10} M_{b}$. In this model only $2.2 \%$ of the variance is explained, and the exponent is barely larger than 0 , suggesting very weak effects of body mass on $N_{\text {chews }}$. Nevertheless, when this increase is calculated across the three orders of magnitude spanned by primate body masses, increases in $N_{\text {chews }}$ are observed. To make this intuitive: a $100 \mathrm{~g}$ primate is predicted to spend $12 \%$ of its time feeding, with a chew cycle time of 0.249 s, yielding $c a .21,700$ chews in a 12$\mathrm{h}$ day; a $1-\mathrm{kg}$ primate is predicted to spend $19 \%$ of its time feeding, with a chew cycle time of $0.327 \mathrm{~s}$, yielding ca. 25,000 chews in a 12-h day; a 10-kg primate spends $29 \%$ of its time feeding, has a chew cycle time of $0.430 \mathrm{~s}$, and $c a .29,000$ chews in a $12-\mathrm{h}$ day; and a $100-\mathrm{kg}$ primate spends $44 \%$ of its time feeding, has a chew cycle time of $0.565 \mathrm{~s}$, and chews $c a$. 34,000 times in a 12-h day. This represents a $53 \%$ increase in $N_{\text {chews }}$ across the three orders of magnitude in primate body mass.

This scaling of $N_{\text {chews }}$ supports the hypothesis that larger primates chew more than smaller ones (Hylander 1979a; Hylander et al. 2011; Ravosa 1991, 1992; Ravosa et al. 2000b), but it is not obvious that the magnitude of this effect is likely to result in fatigue damage in the mandible. For example, using regression equations relating the number of cycles to failure to strain magnitude in human bone $\left(\log _{10} N_{\text {cycles }}=79.8-\right.$ $20.1 \log _{10}$ strain) (Zioupos et al. 2001), at least $10^{12}$ cycles are needed to cause fatigue fracture of the mandible at a tensile strain magnitude of $2000 \mu \varepsilon$ and a loading frequency of $0.5 \mathrm{~Hz}$. At a tensile strain magnitude of $3000 \mu \varepsilon, 10^{10}$ cycles are needed 
to produce fracture. Even this latter number is orders of magnitude more cycles than it is even possible for the largest primates to generate chewing $24 \mathrm{~h} / \mathrm{d}$ all their lives. Thus, if extrapolation of the equations of Zioupos et al. below their sampled strain magnitude is even approximately correct, the primate mandible is unlikely to fracture from fatigue damage within a primate's lifetime, and size-related changes in mandible morphology do not function to decrease the risk of fatigue fracture in the primate mandible.

If size-related changes in mandibular morphology are not adaptations to resist fatigue fracture, then two alternative explanations should be considered. First, if jaw muscle physiological cross-sectional area (PCSA) scaled with negative allometry (Cachel 1984), then size-related increases in symphyseal fusion might reflect increased efficiency of transfer of balancing side muscle force to the working side bite point (Hylander 1985; Hylander et al. 2011; Ravosa 1991). However, the data do not support a hypothesis of negative allometry of jaw muscle PCSA (Anapol et al. 2008; Antón 1999, 2000; Perry and Wall 2008; Perry et al. 2011). Second, mandibles of larger primates may be designed to resist larger external forces needed to process a "tougher" diet (Hylander 1979b; Hylander et al. 1991a; Hylander and Johnson 1997; Ravosa et al. 2000a; Ross and Hylander 1996; Ross et al. 2011; Weijs and De Jong 1977). The available data on scaling of primate dietary toughness are not sufficient to evaluate this hypothesis, but this remains a possibility.

\section{Future Research}

On the basis of this literature review, conclusions by other workers, and the results presented here, we suggest that a clear picture of the relationship between dietary categories and mandibular morphology will emerge only once better data are collected from several levels in the conceptual hierarchy (Fig. 1). The recent proliferation of studies of food geometric and material properties of wild primates has not been accompanied by improved understanding of relationships between diet and mandible morphology. We suspect this is because food geometric and material properties impact mandibular morphology only through deeper levels in our hierarchy (Fig. 1); i.e., by altering feeding behavior, e.g., by necessitating more ingestion related food processing, and/or by altering the loading regime associated with a given behaviors, e.g., altering bite force orientation by altering jaw movement patterns during mastication. To address these deficiencies, better data are needed on exactly how wild primate feeding behavior is related to food geometric and material properties (Vogel et al. 2008; Wright et al. 2009), how these behaviors are related to loading regimes in wild and laboratory primates (Hylander 1979b; Hylander et al. 2000a,b, 2002; 2004; Vinyard et al. 2011; Vinyard et al. 2008b; Williams et al. 2008), and how these loading regimes are related to patterns of stress and strain in vivo and in silico (Hylander et al. 1987, 1998).

The lack of this information is exemplified by our poor understanding of the implications of primate "feeding time" data, $T_{f}$, for mandibular morphology. In this article we used $T_{f}$ and $T_{c}$ scaling to answer a simple question: Do larger primates chew more during the day $\left(N_{\text {chew }}\right)$ than smaller primates? As we have pointed out 
previously (Ross et al. 2009a, b), our estimate of $N_{\text {chew }}$ scaling across primates is deficient in several ways. First, our estimates of $T_{f}$ and $T_{c}$ scaling were associated with large confidence limits. Data on actual daily chew numbers from wild, zoo, and laboratory primates, and how these vary with diet and food geometric and material properties are clearly needed. Second, our estimate of $N_{\text {chew }}$ scaling will be an accurate estimate of the number of daily loading cycles of the mandible only if chew cycle durations are similar to the durations of other jaw movement cycles during feeding, such as ingestion. Obviously, feeding time can be used in different ways, depending on species, sex, age, individual, and the food being eaten. For example, some foods might require extensive extraction from their protective coverings, with comparatively less time spent chewing, while other foods are easily ingested but might need to be chewed for a long time in preparation for swallowing. In sum, "feeding time" is certainly used differently by different categories of individuals. Exactly how this impacts estimates of fatigue of the mandible during feeding remains to be shown. Third, the estimates of daily feeding time taken from the literature were averages and did not account for variation on seasonal or larger time scales. Better data on use of feeding time during times of food scarcity, or when primates are using fallback food resources would be welcome (Grine et al. 2006; Ungar 2004). Fourth, although the vast majority of our subjects fed themselves by hand in free-ranging contexts, a small number of our estimates of chew cycle time might be affected by restraint, sedation, and surgery (Fish and Mendel 1982; Thompson et al. 2011). Better estimates of chew cycle time from a wide range of wild primates would be valuable. Finally, the fatigue properties of primate mandibular bone are unstudied. In particular, the stress magnitudes, number of cycles experienced per day, and initial sizes of flaws in primate mandibles are needed before the danger of fatigue damage to the primate mandible can be realistically assessed (Ritchie et al. 2005).

\section{Conclusions}

We are not impressed by the relationships between dietary categories and mandibular morphology. We suspect that this is because variation in primate diets is associated with variation in mandibular morphology only when there is also variation in feeding behavior that produces variation in loading regimes acting on the mandible. Because we have a poor understanding of differences in the loading regimes associated with differences in diet, food geometric and material properties, and feeding behaviors, clear associations between specific features of mandible morphology and either categories of food in, or material properties of, primate diets are weak or nonexistent. Ultimately, an understanding of the relationships between diet and mandible morphology will emerge only when dietary categories are mapped to food material and geometric properties; when these properties are linked to specific feeding behaviors; when the number of jaw movement cycles spent by wild primates on these different feeding behaviors are estimated; and when the impact of these different behaviors on loading, stress, and strain regimes in captive, wild, or in silico primate mandibles are calculated (Fig. 1). 
Acknowledgments We thank David Reed, Kazutaka Takahashi, McKenna Konecki, and Maryam Saleh, who assisted with data collection. This work was funded by NSF Physical Anthropology (NSF BCS 0240865) (CFR, Co-PI), an NSF HOMINID grant (BCS 0725147) (CFR, Co-PI), and a grant from the Brain Research Foundation at the University of Chicago to C. F. Ross and Nicho Hatsopoulos. C. F. Ross thanks Erin Vogel and Janine Chalk for the invitation to participate in the workshop in Washington, DC, and Andrea Taylor and Peter Ungar for feedback on some of the ideas presented here. We thank Laura Porro for assistance with segmenting CT scans of primate mandibles.

\section{References}

Agrawal, K. R., Lucas, P. W., Bruce, I. C., \& Prinz, J. F. (1998). Food properties that influence neuromuscular activity during human mastication. Journal of Dental Research, 77(11), 1931-1938.

Agrawal, K. R., Lucas, P. W., \& Bruce, I. C. (2000). The effects of food fragmentation index on mandibular closing angle in human mastication. Archives of Oral Biology, 45(7), 577-584.

Anapol, F., Shahnoor, N., \& Ross, C. F. (2008). Scaling of reduced physiologic cross-sectional area in primate muscles of mastication. In C. Vinyard, C. E. Wall, \& M. J. Ravosa (Eds.), Primate craniofacial function and biology (pp. 201-216). New York: Springer.

Antón, S. C. (1996). Cranial adaptation to a high attrition diet in Japanese macaques. International Journal of Primatology, 17, 401-427.

Antón, S. C. (1999). Macaque masseter muscle: internal architecture, fiber length, and cross-sectional area. International Journal of Primatology, 20, 441-462.

Antón, S. C. (2000). Macaque pterygoid muscles: internal architecture, fiber length, and cross-sectional area. International Journal of Primatology, 21, 131-156.

Arnold, C., Matthews, L. J., \& Nunn, C. L. (2010). The 10ktrees website: a new online resource for primate phylogeny. Evolutionary Anthropology, 19, 114-118.

Bouvier, M. (1986a). A biomechanical analysis of mandibular scaling in Old World monkeys. American Journal of Physical Anthropology, 69, 473-482.

Bouvier, M. (1986b). Biomechanical scaling of mandibular dimensions in New World monkeys. International Journal of Primatology, 7, 551-567.

Bouvier, M., \& Hylander, W. L. (1981a). Effect of bone strain on cortical bone structure in macaques (Macaca mulatta). Journal of Morphology, 167(1), 1-12.

Bouvier, M., \& Hylander, W. L. (1981b). The effect of dietary consistency on the morphology of the mandibular condylar cartilage in macaques. American Journal of Physical Anthropology, 54(2), 203-204.

Bouvier, M., \& Hylander, W. L. (1984). The effect of dietary consistency on gross and histologic morphology in the craniofacial region of young rats. The American Journal of Anatomy, 170(1), $117-126$.

Brown, B. (1997). Miocene hominoid mandibles - functional and phylogenetic perspectives. In D. R. Begun, C. V. Ward, \& M. D. Rose (Eds.), Function, phylogeny and fossils: Miocene hominoid evolution and adaptation (pp. 153-171). New York: Plenum.

Cachel, S. (1984). Growth and allometry in primate masticatory muscles. Archives of Oral Biology, 29, 287-293.

Daegling, D. J. (1992). Mandibular morphology and diet in the genus Cebus. International Journal of Primatology, 13, 545-570.

Daegling, D. J. (2002). Bone geometry in cercopithecoid mandibles. Archives of Oral Biology, 47(4), 315-325.

Daegling, D. J. (2007). Relationship of bone utilization and biomechanical competence in hominoid mandibles. Archives of Oral Biology, 52(1), 51-63.

Daegling, D. J., \& Grine, F. E. (2006). Mandibular biomechanics and the paleontological evidence for the evolution of human diet. In P. S. Ungar (Ed.), Evolution of the human diet: The known, the unknown, and the unknowable (pp. 77-105). New York: Oxford University Press.

Daegling, D. J., \& McGraw, W. S. (2000). Gnathic morphology and feeding ecology in papionin primates. American Journal of Physical Anthropology, 30(Supplement), 134.

Daegling, D. J., \& McGraw, W. S. (2001). Feeding, diet, and jaw form in West African Colobus and Procolobus. International Journal of Primatology, 22(6), 1033-1055.

Daegling, D. J., \& McGraw, W. S. (2007). Functional morphology of the mangabey mandibular corpus: relationship to dental specializations and feeding behavior. American Journal of Physical Anthropology, 134(1), 50-62. 
Darvell, B. W., Lee, P. K. D., Yuen, T. D. B., \& Lucas, P. W. (1996). A portable fracture toughness tester for biological materials. Measurement Science and Technology, 7, 954-962.

De Jong, W. C. (2011). The physiology of habitual bone strains. Amsterdam: University of Amsterdam.

de Jong, W. C., Koolstra, J. H., Korfage, J. A. M., van Ruijven, L. J., \& Langenbach, G. E. J. (2010). The daily habitual in vivo strain history of a non-weight-bearing bone. Bone, 46(1), 196-202.

Doncaster, C.P., \& Davey, A. J. H. (2007). Analysis of variance and covariance : How to choose and construct models for the life sciences. Cambridge: Cambridge University Press.

Felsenstein, J. (1985). Phylogenies and the comparative method. American Naturalist, 125, 1-15.

Fish, D. R., \& Mendel, F. C. (1982). Mandibular movement patterns relative to food types in common tree shrews (Tupaia glis). American Journal of Physical Anthropology, 58, 255-269.

Foster, K. D., Woda, A., \& Peyron, M. A. (2006). Effect of texture of plastic and elastic model foods on the parameters of mastication. Journal of Neurophysiology, 95(6), 3469-3479.

Freckleton, R. P., Harvey, P. H., \& Pagel, M. (2002). Phylogenetic analysis and comparative data: a test and review of evidence. American Naturalist, 160, 712-726.

Gallo, L. M. (2005). Modeling of temporomandibular joint function using MRI and jaw-tracking technologies-Mechanics. Cells, Tissues, Organs, 180(1), 54.

Gallo, L. M., Airoldi, G. B., Airoldi, R. L., \& Palla, S. (1997). Description of mandibular finite helical axis pathways in asymptomatic subjects. Journal of Dental Research, 76(2), 704-713.

Gallo, L. M., Fushima, K., \& Palla, S. (2000). Mandibular helical axis pathways during mastication. Journal of Dental Research, 79(8), 1566-1572.

Garland, T., \& Ives, A. R. (2000). Using the past to predict the present: confidence intervals for regression equations in phylogenetic comparative methods. American Naturalist, 155(3), 346-364.

Grine, F. E., Ungar, P. S., Teaford, M. F., \& El-Zaatari, S. (2006). Molar microwear in Praeanthropus afarensis: evidence for dietary stasis through time and under diverse paleoecological conditions. Journal of Human Evolution, 51(3), 297-319.

Hiiemae, K. M. (1978). Mammalian mastication: A review of the activity of jaw muscles and the movements they produce in chewing. In P. M. Butler \& K. Joysey (Eds.), Development, function and evolution of teeth (pp. 359-398). London: Academic Press.

Hiiemae, K. M., \& Crompton, A. W. (1985). Mastication, food transport, and swallowing. In M. Hildebrand, D. M. Bramble, K. F. Liem, \& D. B. Wake (Eds.), Functional vertebrate morphology (pp. 262-290). Cambridge: Belknap Press.

Hiiemae, K. M., \& Kay, R. F. (1973). Evolutionary trends in the dynamics of primate mastication. In M. R. Zingeser (Ed.), Fourth international congress of primatology (Craniofacial biology of primates, Vol. 3, pp. 28-64). Basel: Karger.

Hogue, A. S. (2008). Mandibular corpus form and its functional significance: Evidence from marsupials. In C. Vinyard, M. J. Ravosa, \& C. E. Wall (Eds.), Primate craniofacial function and biology (pp. 329356). New York: Springer.

Huelsenbeck, J. P., Rannala, B., \& Masly, J. P. (2000). Accommodating phylogenetic uncertainty in evolutionary studies. Science, 288, 2349-2350.

Hylander, W. L. (1979a). The functional significance of primate mandibular form. Journal of Morphology, 160, 223-240.

Hylander, W. L. (1979b). Mandibular function in Galago crassicaudatus and Macaca fascicularis: an in vivo approach to stress analysis of the mandible. Journal of Morphology, 159, 253-296.

Hylander, W. L. (1984). Stress and strain in the mandibular symphysis of primates: a test of competing hypotheses. American Journal of Physical Anthropology, 64, 1-46.

Hylander, W. L. (1985). Mandibular function and biomechanical stress and scaling. American Zoologist, $25,315-330$.

Hylander, W. L. (1988). Implications of in vivo experiments for interpreting the functional significance of "robust" australopithecine jaws. In F. E. Grine (Ed.), Evolutionary history of the "robust" australopithecines (pp. 55-83). New York: Aldine de Gruyter.

Hylander, W. L., \& Johnson, K. R. (1997). In vivo bone strain patterns in the zygomatic arch of macaques and the significance of these patterns for functional interpretations of craniofacial form. American Journal of Physical Anthropology, 102, 203-232.

Hylander, W. L., \& Ravosa, M. J. (1992). An analysis of the supraorbital region of primates: A morphometric and experimental approach. In P. Smith \& E. Tchernov (Eds.), Structure, function and evolution of teeth (pp. 223-255). London: Freund.

Hylander, W. L., Johnson, K. R., \& Crompton, A. W. (1987). Loading patterns and jaw movements during mastication in Macaca fascicularis: a bone-strain, electromyographic, and cineradiographic analysis. American Journal of Physical Anthropology, 72, 287-314. 
Hylander, W. L., Picq, P. G., \& Johnson, K. R. (1991a). Function of the supraorbital region of primates. Archives of Oral Biology, 36(4), 273-281.

Hylander, W. L., Picq, P. G., \& Johnson, K. R. (1991b). Masticatory-stress hypotheses and the supraorbital region of primates. American Journal of Physical Anthropology, 86, 1-36.

Hylander, W. L., Ravosa, M. J., Ross, C. F., \& Johnson, K. R. (1998). Mandibular corpus strain in Primates: further evidence for a functional link between symphyseal fusion and jaw-adductor muscle force. American Journal of Physical Anthropology, 107, 257-271.

Hylander, W. L., Ravosa, M. J., Ross, C. F., Wall, C. E., \& Johnson, K. R. (2000a). Jaw-muscle recruitment patterns during mastication in anthropoids and prosimians. American Journal of Physical Anthropology, 30(Supplement), 185.

Hylander, W. L., Ravosa, M. J., Ross, C. F., Wall, C. E., \& Johnson, K. R. (2000b). Symphyseal fusion and jaw-adductor muscle force: an EMG study. American Journal of Physical Anthropology, 112(4), 469492.

Hylander, W. L., Vinyard, C. J., Wall, C. E., Williams, S. H., \& Johnson, K. R. (2002). Recruitment and firing patterns of jaw muscles during mastication in ring-tailed lemurs. American Journal of Physical Anthropology, Supplement, 34, 88.

Hylander, W. L., Ravosa, M. J., \& Ross, C. F. (2004). Jaw muscle recruitment patterns during mastication in anthropoids and prosimians. In F. Anapol, R. Z. German, \& N. G. Jablonski (Eds.), Shaping primate evolution (pp. 229-257). Cambridge: Cambridge University Press.

Hylander, W. L., Vinyard, C. J., Wall, C. E., Williams, S. H., \& Johnson, K. R. (2011). Functional and evolutionary significance of the recruitment and firing patterns of the jaw adductors during chewing in verreaux's sifaka (Propithecus verreauxi). American Journal of Physical Anthropology, 145(4), 531-547.

Iriarte-Diaz, J., Reed, D. A., \& Ross, C. F. (2011). Sources of variance in temporal and spatial aspects of jaw kinematics in two species of primates feeding on foods of different properties. Integrative and Comparative Biology. 51(2), 307-319.

Kay, R. F. (1975). The functional adaptations of primate molar teeth. American Journal of Physical Anthropology, 43, 195-216.

Kay, R. F. (1984). On the use of anatomical features to infer foraging behavior in extinct primates. In P. S. Rodman \& J. G. Cant (Eds.), Adaptations for foraging in nonhuman primates (pp. 21-53). New York: Columbia University Press.

Kay, R. F. (1985). Dental evidence for the diet of Australopithecus. Annual Review of Anthropology, 14, $315-341$.

Kay, R. F., \& Hiiemae, K. M. (1974). Jaw movement and tooth use in recent and fossil primates. American Journal of Physical Anthropology, 40(2), 227-256.

Kay, R. F., \& Hylander, W. L. (1978). The dental structure of mammalian folivores with special reference to Primates and Phalangeroidea (Marsupialia). In G. G. Montgomery (Ed.), The biology of arboreal folivores (pp. 173-191). Washington, DC: Smithsonian Institution Press.

Kay, R. F., \& Ungar, P. S. (1997). Dental evidence for diet in some Miocene catarrhines with comments on the effects of phylogeny on the interpretation of adaptation. In D. R. Begun, C. V. Ward, \& M. D. Rose (Eds.), Function, phylogeny, and fossils: Miocene hominoid evolution and adaptations (pp. 131-151). New York: Plenum Press.

Kay, R. F., Schmitt, D., Vinyard, C., Perry, J., Shigehara, N., Takai, M., et al. (2004). The paleobiology of Amphipithecidae, South Asian late Eocene primates. Journal of Human Evolution, 46, 3-25.

Lucas, P. W. (1979). The dental-dietary adaptations of mammals. Neues Jarhbuch für Geologie und Paleontologie, 8, 486-512.

Lucas, P. W. (2004). Dental functional morphology: How teeth work. Cambridge: Cambridge University Press.

Lucas, P. W., \& Teaford, M. F. (1994). The functional morphology of colobine teeth. In J. Oates \& A. G. Davies (Eds.), Colobine monkeys: Their evolutionary ecology (pp. 173-203). Cambridge: Cambridge University Press.

Lucas, P. W., Beta, T., Darvell, B. W., Dominy, N. J., Essackjee, H. C., Lee, P. K. D., et al. (2001). Field kit to characterize physical, chemical and spatial aspects of potential foods of primates. Folia Primatologica, 72, 11-15.

Lucas, P. W., Constantino, P., \& Wood, B. (2008). Inferences regarding the diet of extinct hominins: structural and functional trends in dental and mandibular morphology within the hominin clade. Journal of Anatomy, 212, 486-500.

Lucas, P. W., Constantino, P. J., Chalk, J., Ziscovici, C., Wright, B. W., Fragaszy, D. M., et al. (2009). Indentation as a technique to assess the mechanical properties of fallback foods. American Journal of Physical Anthropology, 140(4), 643-652. 
Lutzoni, F., Pagel, M., \& Reeb, V. (2001). Major fungal lineages are derived from lichen symbiotic ancestors. Nature, 411, 937-940.

Norconk, M. A., Wright, B. W., Conklin-Brittain, N. L., \& Vinyard, C. J. (2009). South American primates: Testing new theories in the study of primate behavior, ecology, and conservation. In A. Estrada, P. A. Garber, J. C. Bicca-Marques, E. Heymann, \& K. Strier (Eds.), Mechanical and nutritional properties of foods as factors in platyrrhine dietary adaptations (pp. 279-319). New York: Springer.

Nunn, C. L. (2011). The comparative approach in evolutionary anthropology and biology. Chicago: University of Chicago Press.

Organ, C., Nunn, C. L., Machanda, Z., \& Wrangham, R. W. (2011). Phylogenetic rate shifts in feeding time during the evolution of Homo. Proceedings of the National Academy of Sciences of the USA, 108(35), $14555-14559$.

Pagel, M. (1999). Inferring the historical patterns of biological evolution. Nature, 401, 877-884.

Pagel, M., \& Lutzoni, F. (2002). Accounting for phylogenetic uncertainty in comparative studies of evolution and adaptation. In M. Laessig \& A. Valleriani (Eds.), Biological evolution and statistical physics (pp. 148-161). Berlin: Springer-Verlag.

Pagel, M., \& Meade, A. (2007). BayesTraits (www.evolution.rdg.ac.uk) (Version 1.0). Reading, UK.

Perry, J. M. G., \& Wall, C. E. (2008). Scaling of the chewing muscles in prosimians. In C. Vinyard, M. J. Ravosa, \& C. E. Wall (Eds.), Primate craniofacial function and biology (pp. 217-240). New York: Springer.

Perry, J. M. G., Hartstone-Rose, A., \& Wall, C. E. (2011). The jaw adductors of strepsirrhines in relation to body size, diet, and ingested food size. The Anatomical Record: Advances in Integrative Anatomy and Evolutionary Biology, 294(4), 712-728.

Plesh, O., Bishop, W., \& McCall, W. (1986). Effect of gum hardness on chewing pattern. Experimental Neurology, 92(3), 502-512.

Rambaut, A., \& Drummond, H. (2003-2009). Tracer: MCMC Trace Analysis Tool (Version 1.5.0).

Ravosa, M. J. (1988). Browridge development in Cercopithecidae: a test of two models. American Journal of Physical Anthropology, 76, 535-555.

Ravosa, M. J. (1990). Functional assessment of subfamily variation in maxillomandibular morphology among Old-World monkeys. American Journal of Physical Anthropology, 82(2), 199-212.

Ravosa, M. J. (1991). Structural allometry of the mandibular corpus and symphysis in prosimian primates. Journal of Human Evolution, 20, 3-20.

Ravosa, M. J. (1992). Allometry and heterochrony in extant and extinct Malagasy primates. Journal of Human Evolution, 23(2), 197-217.

Ravosa, M. J. (1996). Jaw morphology and function in living and fossil Old World monkeys. International Journal of Primatology, 17(6), 909-932.

Ravosa, M. J. (2000). Size and scaling in the mandible of living and extinct apes. Folia Primatologica, 71 (5), 305-322.

Ravosa, M. J., Johnson, K. R., \& Hylander, W. L. (2000a). Strain in the galago facial skull. Journal of Morphology, 245, 51-66.

Ravosa, M. J., Vinyard, C. J., Gagnon, M., \& Islam, S. A. (2000b). Evolution of anthropoid jaw loading and kinematic patterns. American Journal of Physical Anthropology, 112(4), 493-516.

Ravosa, M. J., Kunwar, R., Stock, S. R., \& Stack, M. S. (2007). Pushing the limit: masticatory stress and adaptive plasticity in mammalian craniomandibular joints. Journal of Experimental Biology, 210(4), 628-641.

Ravosa, M. J., Ning, J., Costley, D. B., Daniel, A. N., Stock, S. R., \& Stack, M. S. (2010). Masticatory biomechanics and masseter fiber-type plasticity. Journal of Musculoskeletal \& Neuronal Interactions, 10(1), 46-55.

R-Development-Core-Team. (2010). R: A language and environment for statistical computing. Vienna: R Foundation for Statistical Computing.

Reed, D. A., \& Ross, C. F. (2010). The influence of food material properties on jaw kinematics in the primate, Cebus. Archives of Oral Biology, 55, 946-962.

Ritchie, R. O., Kinney, J. H., Kruzic, J. J., \& Nalla, R. K. (2005). A fracture mechanics and mechanistic approach to the failure of cortical bone. Fatigue and Fracture of Engineering Materials and Structures, $28,345-371$.

Ross, C. F. (2001). In vivo function of the craniofacial haft: the interorbital "pillar. American Journal of Physical Anthropology, 116, 108-139.

Ross, C. F., Dharia, R., Herring, S. W., Hylander, W. L., Liu, Z.-J., Rafferty, K. L., Ravosa, M. J., \& Williams, S. H. (2007a). Modulation of mandibular loading and bite force in mammals during mastication. Journal of Experimental Biology, 210, 1046-1063. 
Ross, C. F., Eckhardt, A., Herrel, A., Hylander, W. L., Metzger, K. A., Schaerlaeken, V., Washington, R. L., \& Williams, S. H. (2007b). Modulation of intra-oral processing in mammals and lepidosaurs. Integrative and Comparative Biology, 47, 118-136.

Ross, C. F., \& Hylander, W. L. (1996). In vivo and in vitro bone strain in the owl monkey circumorbital region and the function of the postorbital septum. American Journal of Physical Anthropology, 101(2), $183-215$.

Ross, C. F., \& Metzger, K. A. (2004). Bone strain gradients and optimization in tetrapod skulls. Annals of Anatomy, 186, 387-396.

Ross, C. F., Henneberg, M., Ravosa, M. J., \& Richard, S. (2004). Curvilinear, geometric and phylogenetic modeling of basicranial flexion: is it adaptive, is it constrained? Journal of Human Evolution, 46(2), $185-213$.

Ross, C. F., Reed, D. A., Washington, R. L., Eckhardt, A., Anapol, F., \& Shahnoor, N. (2009a). Scaling of chew cycle duration in primates. American Journal of Physical Anthropology, 138(1), 30-44.

Ross, C. F., Washington, R. L., Eckhardt, A., Reed, D. A., Vogel, E., Dominy, N. J., et al. (2009b). Ecological consequences of scaling of chew cycle duration and daily feeding time in Primates. Journal of Human Evolution, 56, 570-585.

Ross, C. F., Berthaume, M. A., Dechow, P. C., Iriarte-Diaz, J., Porro, L. B., Richmond, B. G., et al. (2011). In vivo bone strain and finite-element modeling of the craniofacial haft in catarrhine primates. Journal of Anatomy, 218(1), 112-148.

Searle, S. R., Casella, G., \& McCulloch, C. E. (2006). Variance components. 3rd ed. New York: Wiley.

Shah, N. (2003). Foraging strategies in two sympatric mangabey species (Cercocebus agilis and Lophocebus albigena). Stony Brook: Stony Brook University.

Sokal, R. R., \& Rohlf, F. J. (1995). Biometry: The principles and practice of statistics in biological research. New York: W. H. Freeman and Co.

Spoor, C. W., \& Veldpaus, F. E. (1980). Rigid body motion calculated from spatial co-ordinates of markers. Journal of Biomechanics, 13(4), 391.

Strait, S. G. (1993a). Differences in occlusal morphology and molar size in frugivores and faunivores. Journal of Human Evolution, 25, 471-484.

Strait, S. G. (1993b). Molar morphology and food texture among small-bodied insectivorous mammals. Journal of Mammalogy, 74, 391-402.

Strait, D. S., Weber, G. W., Neubauer, S., Chalk, J., Richmond, B. G., Lucas, P. W., et al. (2009). The feeding biomechanics and dietary ecology of Australopithecus africanus. Proceedings of the National Academy of Sciences of the USA, 106(7), 2124-2129.

Taylor, A. B. (2002). Masticatory form and function in the African apes. Americal Journal of Physical Anthropology, 117, 133-156.

Taylor, A. B., \& Vinyard, C. J. (2004). Comparative analysis of masseter fiber architecture in tree-gouging (Callithrix jacchus) and nongouging (Saguinus oedipus) callitrichids. Journal of Morphology, 261(3), 276-285.

Taylor, A. B., \& Vinyard, C. J. (2008). The relationship between jaw-muscle fiber architecture and feeding behavior in primates: Tree-gouging and nongouging gummivorous callitrichids as a natural experiment. In C. J. Vinyard, M. J. Ravosa, \& C. E. Wall (Eds.), Primate craniofacial function and biology (pp. 241-264). New York: Springer.

Taylor, A. B., \& Vinyard, C. J. (2009). Jaw-muscle fiber architecture in tufted capuchins favors generating relatively large muscle forces without compromising jaw gape. Journal of Human Evolution, 57(6), $710-720$.

Taylor, A. B., Jones, K. E., Kunwar, R., \& Ravosa, M. J. (2006). Dietary consistency and plasticity of masseter fiber architecture in postweaning rabbits. The Anatomical Record. Part A, Discoveries in Molecular, Cellular, and Evolutionary Biology, 128, 1105-1111.

Taylor, A. B., Vogel, E. R., \& Dominy, N. J. (2008). Food material properties and mandibular load resistance abilities in large-bodied hominoids. Journal of Human Evolution, 55(4), 604-616.

Teaford, M. F., \& Ungar, P. S. (2000). Diet and the evolution of the earliest human ancestors. PNAS, 97(25), $13506-13511$.

Terhune, C. E. (2009). Scaling relationships in the anthropoid temporomandibular joint. American Journal of Physical Anthropology, 48(Supplement), 254.

Terhune, C. E. (2010). The temporomandibular joint in anthropoid primates: Functional, allometric, and phylogenetic influences. Phoenix: Arizona State University.

Terhune, C. E., Iriarte-Diaz, J., Taylor, A. B., \& Ross, C. F. (2011). The instantaneous center of rotation of the mandible in non-human primates. Integrative and Comparative Biology in press. 
Thompson, C. L., Donley, E. M., Stimpson, C. D., Horne, W. I., \& Vinyard, C. J. (2011). The influence of experimental manipulations on chewing speed during in vivo laboratory research in tufted capuchins (Cebus apella). American Journal of Physical Anthropology, 145(3), 402-414.

Ungar, P. S. (2004). Dental topography and diets of Australopithecus afarensis and early Homo. Journal of Human Evolution, 46(5), 605-622.

Ungar, P. S., \& Spencer, M. (1999). Incisor microwear, diet, and tooth use in three Amerindian populations. American Journal of Physical Anthropology, 109(3), 387-396.

Ungar, P. S., \& Sponheimer, M. (2011). The diets of early hominins. Science, 334(6053), 190-193.

Ungar, P. S., Grine, F., \& Teaford, M. F. (2006). Diet in early Homo: a review of the evidence and a new model of adaptive versatility. Annual Review of Anthropology, 35, 209-228.

Vinyard, C. J., \& Ryan, T. M. (2006). Cross-sectional bone distribution in the mandibles of gouging and non-gouging Platyrrhini. International Journal of Primatology, 27(5), 1461-1490.

Vinyard, C. J., Wall, C. E., Williams, S. H., \& Hylander, W. L. (2003). Comparative functional analysis of skull morphology of tree-gouging primates. American Journal of Physical Anthropology, 120, 153170.

Vinyard, C. J., Wall, C. E., Williams, S. H., \& Hylander, W. L. (2008a). Patterns of variation across primates in jaw-muscle electromyography during mastication. Integrative and Comparative Biology, 48(2), 294-311.

Vinyard, C. J., Yamashita, N., \& Tan, C. L. (2008b). Linking laboratory and field approaches in studying the evolutionary physiology of biting in bamboo lemurs. International Journal of Primatology, 29, 1421-1439.

Vinyard, C. J., Taylor, A. B., Teaford, M. F., Glander, K. E., Ravosa, M. J., Rossie, J. B., et al. (2011). Are we looking for loads in all the right places? New research directions for studying the masticatory apparatus of New World monkeys. The Anatomical Record: Advances in Integrative Anatomy and Evolutionary Biology, 294(12), 2140-2157.

Vogel, E. R., van Woerden, J. T., Lucas, P. W., Utami Atmoko, S. S., van Schaik, C. P., \& Dominy, N. J. (2008). Functional ecology and evolution of hominoid molar enamel thickness: Pan troglodytes schweinfurthii and Pongo pygmaeus wurmbii. Journal of Human Evolution, 55, 60-74.

Wall, C. E. (1995). Form and function of the temporomandibular joint in anthropoid primates. Ph.D. dissertation, State University of New York at Stony Brook, Stony Brook, NY.

Wall, C. E. (1999). A model of TMJ function in anthropoid primates based on condylar movements during mastication. Americal Journal of Physical Anthropology, 109, 67-88.

Weijs, W. A., \& De Jong, J. H. (1977). Strain in mandibular alveolar bone during mastication in the rabbit. Archives of Oral Biology, 22, 667-675.

Williams, S. H., Vinyard, C., Glander, K., Deffenbaugh, M., Teaford, M., \& Thompson, C. (2008). Telemetry system for assessing jaw-muscle function in free-ranging primates. International Journal of Primatology, 29(6), 1441-1453.

Williams, S. H., Stover, K. K., Davis, J. S., \& Montuelle, S. J. (2011). Mandibular corpus bone strains during mastication in goats (Capra hircus): a comparison of ingestive and rumination chewing. Archives of Oral Biology, 56, 960-971.

Woda, A., Foster, K., Mishellany, A., \& Peyron, M. A. (2006a). Adaptation of healthy mastication to factors pertaining to the individual or to the food. Physiology \& Behavior, 89(1), 28-35.

Woda, A., Mishellany, A., \& Peyron, M. A. (2006b). The regulation of masticatory function and food bolus formation. Journal of Oral Rehabilitation, 33(11), 840-849.

Wright, B. W., Wright, K. A., Chalk, J., Verderane, M. P., Fragaszy, D., Visalberghi, E., et al. (2009). Fallback foraging as a way of life: using dietary toughness to compare the fallback signal among capuchins and implications for interpreting morphological variation. American Journal of Physical Anthropology, 140(4), 687-699.

Wroe, S., Moreno, K., Clausen, P., McHenry, C., \& Curnoe, D. (2007). High-resolution three-dimensional computer simulation of hominid cranial mechanics. The Anatomical Record: Advances in Integrative Anatomy and Evolutionary Biology, 290(10), 1248-1255.

Yamashita, N. (2008). Food physical properties and their relationship to morphology: The curious case of kily. In C. Vinyard, M. J. Ravosa, \& C. E. Wall (Eds.), Primate craniofacial function and biology (pp. 387-406). New York: Springer.

Zioupos, P., Currey, J. D., \& Casinos, A. (2001). Tensile fatigue in bone: are cycles-, or time to failure, or both, important? Journal of Theoretical Biology, 210(3), 389. 